\title{
Oleuropein an Olive Oil Compound in Acute and Chronic Inflammation Models: Facts and Perspectives
}

\author{
Domenico Britti, Daniela Impellizzeri, \\ Antonio Procopio and Salvatore Cuzzocrea
}

Additional information is available at the end of the chapter

http://dx.doi.org/10.5772/51889

\section{Introduction}

A large mass of research has been accumulating to provide evidence for the health benefits of olive oil feeding and to scientifically support the widespread adoption of traditional Mediterranean diet as a model of healthy eating (Menendez et al., 2007). This evidence has been attributed to the fact that olive oil, the predominant source of fat in the Mediterranean diet (Petroni et al., 1995), contains several minor non-nutrients chemicals such as $\alpha$ - and $\gamma$ tocopherols and $\beta$-carotene, phytosterols, pigments, terpenic acids, flavonoids such as luteolin and quercetin, squalene, and phenolic compounds, usually and incorrectly termed polyphenols (Menendez et al., 2007; Visioli et al., 2002; Trichopoulou et al., 2003; Tripoli et al., 2005; Servili et al., 2004). The main phenolic compounds in virgin olive oil are secoiridoid derivatives of 2-(3,4-dihydroxyphenyl)ethanol (3,4-DHPEA) and 2-(4-hydroxyphenyl)ethanol ( $p$-HPEA) that occur as either simple phenols or esterified with elenolic acid to form, respectively, oleuropein and its derivative demethyloleuropein, and ligstroside, their aglycones 3,4-DHPEA-EA and p-HPEA-EA (Figure 1) (Bendini et al., 2007; Suárez et al., 2009). The aglyconic form of oleuropein and ligstroside, 3,4-DHPEA-EA and $p$-HPEA-EA respectively, were reported for the first time by Montedoro et al, who also assigned their chemical structures, later confirmed by other (Montedoro et al., 1992; Angerosa et al., 1996; Owen et al., 2000). 3,4-DHPEA-EA and $p$-HPEA-EA, associated to the intense sensory of bitterness and pungency respectively attribute in VOO (Gutierrez-Rosales et al., 2003), is endowed with numerous beneficial effects on human health (Servili et al., 2004; Bendini et al., 2007; Esti et al., 1998; Della Ragione et al., 2000; Paiva-Martins et al., 2001; Fabiani et al., 2002; Carasco-Pancorbo et al., 2005; Artajo et al., 2006; Fabiani et al., 2006; Fabiani et al., 2008; Paiva-Martins et al., 2009). 


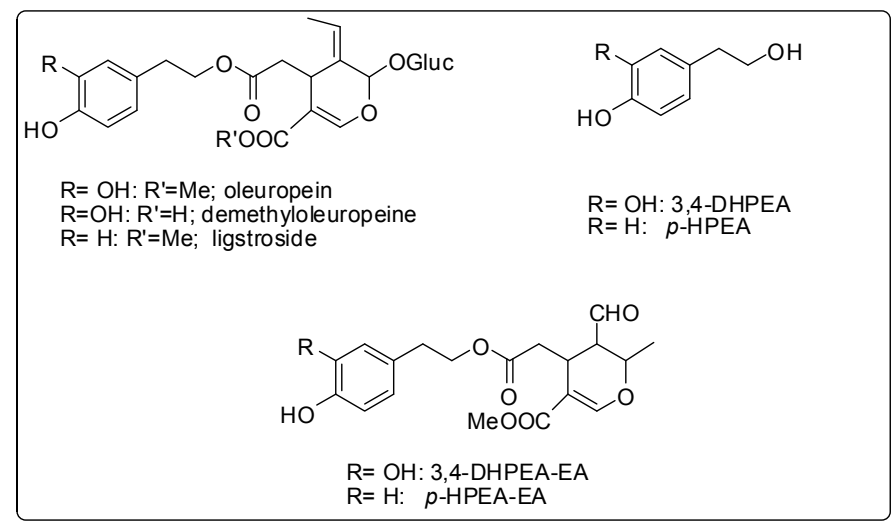

Figure 1. Chemical structures.

In particular, the anti-inflammatory properties of olive oil phenolic compounds seem to overlap with those attributed to non-steroidal anti-inflammatory drugs (Procopio A, et al., 2009). The majority of phenolic compounds found in olive oil or table olives are derived from the hydrolysis of oleuropein, the major phenolic constituent of the leaves and unprocessed olive drupes of Olea europaea and responsible for the bitter taste of immature and unprocessed olives. Concentrations of up to $9.0 \mathrm{mg} / \mathrm{l}$ of oleouropein and $5.6 \mathrm{mg} / \mathrm{l}$ of its hydrolysis product hydroxytyrosol, have been detected in some preparations of olive oil (Montedoro et al., 1992). Oleuropein, a glucoside with hydroxyaromatic functionality, has recognized several pharmacological properties including antioxidant, anti-inflammatory, anti-atherogenic, anti-cancer, antidiabetic, antimicrobial, and antiviral, and for these reasons, it is commercially available as food supplement in Mediterranean countries (Miles et al., 2005; Covas, 2008; Omar, 2010). A more efficient anti-inflammatory role of the aglyconic 3,4-DHPEA-EA compared with the glycosidic form of oleuropein possibly derives from the greater lipophilicity of the former, a property that should allow better cell membrane incorporation and/or interaction with other lipids (Saija et al., 1998). We focused on the antinflammatory properties of 3,4-DHPEA-EA, a hydrolysis product obtained from Oleuropein by the action of $\beta$-glucosidase on the parent glucoside, has been evaluated in a mice model of acute inflammation (carrageenan-induced pleurisy) and in a mice model of chronic inflammation (collagen-induced arthritis) (Impellizzeri et al., 2011a-b).

\section{3,4-DHPEA-EA and acute inflammation}

Premise - The inflammatory reaction is characterized by an initial increase in blood flow to the site of injury, enhanced vascular permeability, production of mediators such us prostaglandins, leukotrienes, histamine, bradykinin, platelet-activating factor (PAF) and the ordered and directional influx and selective accumulation of different effector cells from the peripheral blood at the site of injury. Influx of antigen non-specific but highly destructive cells (neutrophils) is one of the earliest stages of the inflammatory response. Carrageenaninduced local inflammation is commonly used to evaluate anti-inflammatory effects of non- 
steroidal drugs (NSAIDs). Therefore, carrageenan-induced local inflammation (pleurisy) is a useful model to assess the contribution of mediators involved in cellular alterations during the inflammatory process. In particular, the initial phase of acute inflammation $(0-1 \mathrm{~h})$ which is not inhibited by NSAIDs such as indomethacin or aspirin, has been attributed to the release of histamine, 5-hydroxytryptamine and bradykinin, followed by a late phase (1-6 h) mainly sustained by prostaglandin release and attributed to the induction of inducible cyclo-oxygenase (COX-2) in the tissue (Nantel et al., 1999). It appears that the onset of the carrageenan-induced acute inflammation has been linked to neutrophil infiltration and the production of neutrophil-derived free radicals, such as hydrogen peroxide, superoxide and hydroxyl radical, as well as the release of other neutrophil-derived mediators. Free radicals are produced in small amounts by normal cellular processes as part of the mitochondrial electron transport chain and the microsomal cytochrome P-450 system. They are formed during traumatic or hypoxic injuries as a consequence of insufficient oxygenation. Reactive oxygen species (ROS) and reactive nitrogen species (RNS) can react with and subsequently damage proteins, nucleic acids, lipids, and extracellular matrix proteins. During the inflammatory response, ROS and RNS modulate phagocytosis, secretion, gene expression, and apoptosis. Indeed, under pathological circumstances such as acute lung injury and sepsis, excess production of neutrophil-derived ROS and RNS may influence neighbouring endothelial or epithelial cells, contributing to the amplification of inflammatory tissue injury (Fialkow et al., 2007). Furthermore, oxidative stress elicits the activation of the redox-sensitive transcription factors such as nuclear factor- $\kappa \mathrm{B}(\mathrm{NF}-\kappa \mathrm{B})$ and $\mathrm{AP}-1$, that play a central and crucial role in inducing the expression of inflammatory cytokines and intercellular adhesion molecule (ICAM-1) (Chen et al., 2004) and the activation of the redox-sensitive protein kinases such as the mitogen-activated protein kinase (MAPK) superfamily (Li et al., 2002). Thus, the study model was designed to evaluate the effects of 3,4-DHPEA-EA in a mice model of acute inflammation $(0.1 \mathrm{ml}$ of saline containing $2 \% \lambda$ carrageenan was injected into the pleural cavity). In particular, we investigated the effects of 3,4-DHPEA-EA on the lung injury associated with carrageenan induced pleurisy. In order to gain a better insight into the mechanism of action of 3,4-DHPEA-EA, we have also investigated the effects on: 1) lung damage (histology), 2) polymorphonuclear (PMN) infiltration (myeloperoxidase [MPO] activity), 3) ICAM-1 and platelet-adhesion-molecule (P-selectin) expression, 4) nitrotyrosine and poly-ADP-ribose (PAR) formation, 5) proinflammatory cytokines production, tumor necrosis factor- $\alpha$ (TNF- $\alpha)$ and interleukin- $1 \beta$ (IL-1 $\beta), 6)$ lipid peroxidation (malondialdehyde [MDA] levels), and 7) nitric oxide (NO) synthesis (nitrite-nitrate concentration).

\subsection{Materials and methods}

Animals - Male CD mice, weight 20-25 g; Harlan Nossan, Milan, Italy, were used in these studies. The animals were housed in a controlled environment and provided with standard rodent chow and water. Animal care was in compliance with Italian regulations on the protection of animals used for experimental and other scientific purposes (D.lgs 116/92) as well as with EEC regulations (O.J. of E.C. L358/1 12/18/1986). 
Carrageenan-induced pleurisy - Carrageenan-induced pleurisy was induced as previously described (Cuzzocrea et al., 1999). Mice were anaesthetized with isoflurane and subjected to a skin incision at the level of the left sixth intercostals space. The underlying muscle was dissected and saline $(0.1 \mathrm{ml})$ or saline containing $2 \% \lambda$-carrageenan $(0.1 \mathrm{ml})$ was injected into the pleural cavity. The skin incision was closed with a suture and the animals were allowed to recover. At $4 \mathrm{~h}$ after the injection of carrageenan, the animals were killed by inhalation of $\mathrm{CO}_{2}$. The chest was carefully opened and the pleural cavity rinsed with $1 \mathrm{ml}$ of saline solution containing heparin $\left(5 \mathrm{U} \mathrm{ml}^{-1}\right)$ and indomethacin $\left(10 \mu \mathrm{g} \mathrm{ml}^{-1}\right)$. The exudate and washing solution were removed by aspiration and the total volume measured. Any exudate, which was contaminated with blood, was discarded.

Experimental Design - Mice were randomly allocated into the following groups: (i) CAR + saline group. Mice were subjected to carrageenan-induced pleurisy $(\mathrm{N}=10)$; (ii) CAR $+3,4-$ DHPEA-EA group $(100 \mu \mathrm{M} / \mathrm{kg})$. Same as the CAR + saline group but 3,4-DHPEA-EA (100 $\mu \mathrm{M} / \mathrm{kg}$, i.p.) were administered 30min after to carrageenan ( $\mathrm{N}=10)$; (iii) CAR + 3,4-DHPEAEA group $(40 \mu \mathrm{M} / \mathrm{kg})$. Same as the CAR + saline group but 3,4-DHPEA-EA ( $40 \mu \mathrm{M} / \mathrm{kg}$, i.p.) were administered 30min after to carrageenan ( $\mathrm{N}=10$ ); (iv) Sham + saline group. Shamoperated group in which identical surgical procedures to the CAR group was performed, except that the saline was administered instead of carrageenan $(\mathrm{N}=10)$; (v) Sham + 3,4DHPEA-EA group. Same as the Sham+saline group but 3,4-DHPEA-EA (100 $\mu \mathrm{M} / \mathrm{kg}$, i.p.) were administered 30min after to carrageenan $(\mathrm{N}=10)$. The doses of 3,4-DHPEA-EA (40 and $100 \mu \mathrm{M} / \mathrm{kg}$, i.p.) used here were based on previous in vivo studies (Procopio A, et al., 2009).

Histological examination - Lung tissues samples were taken $4 \mathrm{~h}$ after injection of carrageenan. Lung tissues samples were fixed for 1 week in $10 \%$ (w/v) PBS-buffered formaldehyde solution at room temperature, dehydrated using graded ethanol and embedded in Paraplast (Sherwood Medical, Mahwah, NJ, USA). Sections were then deparaffinized with xylene, stained with hematoxylin and eosin. All sections were studied using Axiovision Zeiss (Milan, Italy) microscope.

Measurement of cytokines - TNF- $\alpha$ and IL-1 $\beta$ levels were evaluated in the exudate $4 \mathrm{~h}$ after the induction of pleurisy by carrageenan injection as previously described (Cuzzocrea et al., 1999). The assay was carried out using a colorimetric commercial ELISA kit (CalbiochemNovabiochem Corporation, Milan, Italy).

Measurement of nitrite-nitrate concentration - Total nitrite in exudates, an indicator of NO synthesis, was measured as previously described (Cuzzocrea et al., 2001). Briefly, the nitrate in the sample was first reduced to nitrite by incubation with nitrate reductase $(670 \mathrm{mU} / \mathrm{ml})$ and $\beta$-nicotinamide adenine dinucleotide 3 '-phosphate (NADPH) $(160 \mu \mathrm{M})$ at room temperature for $3 \mathrm{~h}$. The total nitrite concentration in the samples was then measured using the Griess reaction, by adding $100 \mu \mathrm{l}$ of Griess reagent $(0.1 \% \mathrm{w} / \mathrm{v})$ naphthylethylendiamide dihydrochloride in $\mathrm{H}_{2} \mathrm{O}$ and $1 \%(\mathrm{w} / \mathrm{v})$ sulphanilamide in $5 \%(\mathrm{v} / \mathrm{v})$ concentrated $\mathrm{H}_{3} \mathrm{PO}_{4}$; vol. 1:1) to the $100 \mu \mathrm{l}$ sample. The optical density at $550 \mathrm{~nm}\left(\mathrm{OD}_{550}\right)$ was measured using ELISA microplate reader (SLT-Lab Instr., Salzburg, Austria). Nitrite concentrations were calculated by comparison with OD550 of standard solutions of sodium nitrite prepared in $\mathrm{H}_{2} \mathrm{O}$. 
Immunohistochemical localization of ICAM-1, P-selectin, nitrotyrosine and PAR - At the end of the experiment, the tissues were fixed in $10 \%(\mathrm{w} / \mathrm{v})$ PBS-buffered formaldehyde and $8 \mu \mathrm{m}$ sections were prepared from paraffin embedded tissues. After deparaffinization, endogenous peroxidase was quenched with $0.3 \%(\mathrm{v} / \mathrm{v})$ hydrogen peroxide in $60 \%(\mathrm{v} / \mathrm{v})$ methanol for $30 \mathrm{~min}$. The sections were permeablized with $0.1 \%(\mathrm{w} / \mathrm{v})$ Triton X-100 in PBS for $20 \mathrm{~min}$. Non-specific adsorption was minimized by incubating the section in $2 \%(\mathrm{v} / \mathrm{v})$ normal goat serum in PBS for $20 \mathrm{~min}$. Endogenous biotin or avidin binding sites were blocked by sequential incubation for $15 \mathrm{~min}$ with biotin and avidin, respectively. Sections were incubated overnight with anti-nitrotyrosine rabbit polyclonal antibody (Upstate, 1:500 in PBS, v/v), anti-PAR antibody (BioMol, 1:200 in PBS, v/v), anti-ICAM-1 antibody (Santa Cruz Biotechnology, 1:500 in PBS, v/v) or with anti-P-selectin polyclonal antibody (Santa Cruz Biotechnology, 1:500 in PBS, v/v). Sections were washed with PBS, and incubated with secondary antibody. Specific labeling was detected with a biotin-conjugated goat anti-rabbit IgG and avidin-biotin peroxidase complex (Vector Laboratories, DBA). In order to confirm that the immunoreaction for the nitrotyrosine was specific, some sections were also incubated with the primary antibody (anti-nitrotyrosine) in the presence of excess nitrotyrosine $(10 \mathrm{mM})$ to verify the binding specificity. To verify the binding specificity for PAR, ICAM-1, P-selectin, some sections were also incubated with only the primary antibody (no secondary) or with only the secondary antibody (no primary). In these situations no positive staining was found in the sections indicating that the immunoreaction was positive in all the experiments carried out.

MPO activity - MPO activity, an indicator of PMN accumulation, was determined as previously described (Mullane et al., 1985). At the specified time following injection of carrageenan, lung tissues were obtained and weighed, each piece homogenized in a solution containing $0.5 \%(\mathrm{w} / \mathrm{v})$ hexadecyltrimethyl-ammonium bromide dissolved in $10 \mathrm{mM}$ potassium phosphate buffer $\left(\mathrm{pH} \mathrm{7)}\right.$ and centrifuged for $30 \mathrm{~min}$ at $20,000 \times \mathrm{g}$ at $4^{\circ} \mathrm{C}$. An aliquot of the supernatant was then allowed to react with a solution of tetramethylbenzidine

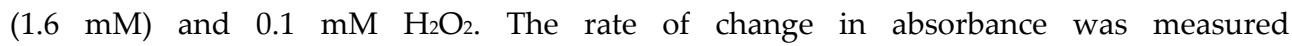
spectrophotometrically at $650 \mathrm{~nm}$. MPO activity was defined as the quantity of enzyme degrading $1 \mu \mathrm{mol}$ of peroxide $\min ^{-1}$ at $37^{\circ} \mathrm{C}$ and was expressed in milliunits per gram weight of wet tissue.

MDA measurement - MDA levels in the lung tissue were determined as an indicator of lipid peroxidation as previously described (Ohkawa et al., 1979). Lung tissue collected at the specified time, was homogenized in $1.15 \%(\mathrm{w} / \mathrm{v}) \mathrm{KCl}$ solution. A $100 \mu \mathrm{l}$ aliquot of the homogenate was added to a reaction mixture containing $200 \mu \mathrm{l}$ of $8.1 \%$ (w/v) SDS, $1.5 \mathrm{ml}$ of $20 \%(\mathrm{v} / \mathrm{v})$ acetic acid ( $\mathrm{pH} 3.5), 1.5 \mathrm{ml}$ of $0.8 \%(\mathrm{w} / \mathrm{v})$ thiobarbituric acid and $700 \mu \mathrm{l}$ distilled water. Samples were then boiled for $1 \mathrm{~h}$ at $95^{\circ} \mathrm{C}$ and centrifuged at 3,000 $\mathrm{g} g$ for $10 \mathrm{~min}$. The absorbance of the supernatant was measured using spectrophotometry at $650 \mathrm{~nm}$.

Materials - Unless otherwise stated, all compounds were obtained from Sigma-Aldrich Company Ltd. (Poole, Dorset, U.K.). 3,4-DHPEA-EA was obtained from the controlled 
hydrolysis of oleuropein extracted from olive leaves by means the patented method reported by Procopio et al. (2009). All other chemicals were of the highest commercial grade available. All stock solutions were prepared in non-pyrogenic saline $(0.9 \% \mathrm{NaCl}$; Baxter, Italy, UK).

Statistical evaluation - All values in the figures and text are expressed as mean standard error (s.e.m.) of the mean of $n$ observations. For the in vivo studies $\mathrm{n}$ represents the number of animals studied. In the experiments involving histology or immunohistochemistry, the figures shown are representative of at least three experiments (histological or immunohistochemistry coloration) performed on different experimental days on the tissue sections collected from all the animals in each group. The results were analyzed by one-way ANOVA followed by a Bonferroni post-hoc test for multiple comparisons. A $p$-value less than 0.05 were considered significant and individual group means were then compared with Student's unpaired t test. A $p$-value of less than 0.05 was considered significant.

\subsection{Results}

Effects of 3,4-DHPEA-EA on carrageenan-induced pleurisy - When compared to lung sections taken from saline-treated animals (sham group Fig. 2A, see histological score 2D) histological examination of lung sections taken from mice treated with carrageenan revealed significant tissue damage and edema (Fig. 2B, see histological score 2D) as well as infiltration of neutrophils (PMNs) within the tissues (Fig. 2B). 3,4-DHPEA-EA (100 $\mu \mathrm{M} / \mathrm{kg}$ ) reduced the degree of lung injury (Fig. 2C, see histological score 2D). The pleural infiltration with PMN appeared to correlate with an influx of leukocytes into the lung tissue, thus we investigated the effect of 3,4-DHPEA-EA on neutrophil infiltration by measurement of MPO activity. MPO activity was significantly elevated at $4 \mathrm{~h}$ after carrageenan administration in vehicle-treated mice (Fig. 2E). Treatment with 3,4-DHPEA-EA significantly attenuated neutrophil infiltration into the lung tissue (Fig. 2E).

Effects of 3,4-DHPEA-EA on the expression of adhesion molecules (ICAM-1, P-selectin) - Staining of lung tissue sections obtained from saline-treated mice with anti-ICAM-1 antibody showed a specific staining along bronchial epithelium demonstrating that ICAM-1 is constitutively expressed (Fig. 3A). No positive staining for P-selectin was found in lung tissue sections from saline-treated mice (Fig. 3D). At $4 \mathrm{~h}$ after carrageenan injection, the ICAM-1 staining intensity increased in the vascular endothelium (Fig. 3B). Lung tissue sections obtained from carrageenan-treated mice showed positive staining for P-selectin localized in the vessels (Fig. 3E). No positive staining for ICAM-1 or P-selectin was observed in the lungs of carrageenan-treated mice treated with 3,4-DHPEA-EA (Fig. 3C and 3F respectively).

Effects of 3,4-DHPEA-EA on the release of pro-inflammatory cytokine and nitrite-nitrate concentration - When compared to sham animals, injection of carrageenan resulted in an increase in the levels of TNF- $\alpha$ and IL-1 $\beta$ in the pleural exudates (Fig. 4A,B). The release of TNF- $\alpha$ and IL-1 $\beta$ was significantly attenuated by treatment with 3,4-DHPEA-EA (Fig. $4 \mathrm{~A}, \mathrm{~B})$. 

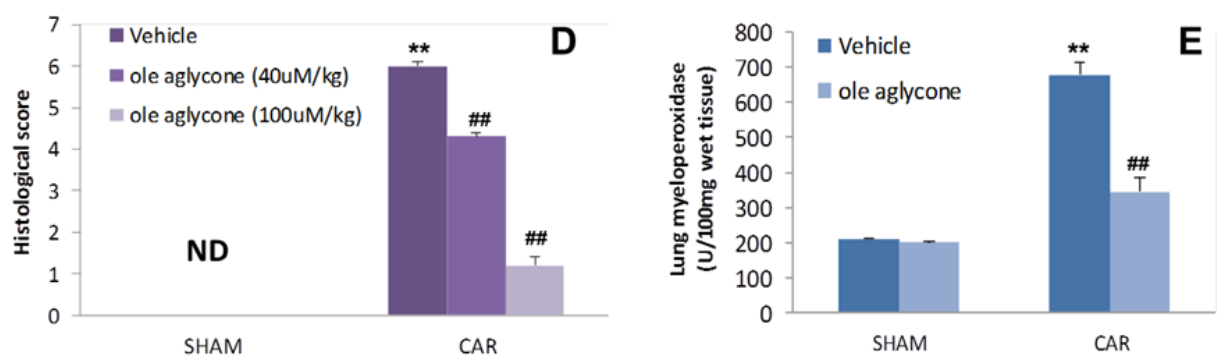

Figure 2. Effect of 3,4-DHPEA-EA (Ole aglycone) on histological alterations of lung tissue $4 \mathrm{~h}$ after carrageenan-induced injury and on PMN infiltration in the lung. Lung sections taken from carrageenantreated mice treated with vehicle demonstrated edema, tissue injury $(B)$ as well as infiltration of the tissue with neutrophils (B). Carrageenan-treated animals treated with 3,4-DHPEA-EA (C) demonstrated reduced lung injury and neutrophil infiltration. Section from sham animals demonstrating the normal architecture of the lung tissue (A). The histological score (D) was made by an independent observer. MPO activity, index of PMN infiltration, was significantly elevated at $4 \mathrm{~h}$ after carrageenan (CAR) administration in vehicle-treated mice (E), if compared with sham mice (E). 3,4DHPEA-EA significantly reduced MPO activity in the lung (E). The figure is representative of at least 3 experiments performed on different experimental days. Data are expressed as mean \pm S.E.M. from $\mathrm{n}=10$ mice for each group. ${ }^{* *}, \mathrm{P}<0.01$ versus sham group. ${ }^{\sharp \#,} \mathrm{P}<0.01$ versus carrageenan.

No significant increase of TNF- $\alpha$ and IL-1 $\beta$ exudates levels was found in the sham animal (Fig. 4A,B). NO levels were also significantly increased in the exudate obtained from mice administered carrageenan (Fig. 4C). Treatment of mice with 3,4-DHPEA-EA significantly reduced NO exudates levels (Fig. 4C). No significant increase of NO exudates levels was found in the sham animal (Fig. 4C).

Effects of 3,4-DHPEA-EA on carrageenan-induced nitrotyrosine formation, lipid peroxidation and poly-ADP-ribosyl polymerase (PARP) activation - Immunohistochemical analysis of lung sections obtained from mice treated with carrageenan revealed positive staining for nitrotyrosine (Fig. 5B). In contrast, no positive staining for nitrotyrosine was found in the lungs of carrageenan-treated mice, which had been treated with 3,4-DHPEAEA $(100 \mu \mathrm{M} / \mathrm{kg})$ (Fig. 5C). In addition, at 4 hours after carrageenan-induced pleurisy, MDA levels were also measured in the lungs as an indicator of lipid peroxidation. As shown in Figure 5D, MDA levels were significantly increased in the lungs of carrageenan-treated mice. Lipid peroxidation was significantly attenuated by the intraperitoneal injection of 3,4-DHPEA-EA (Fig. 5D). At the same time point ( $4 \mathrm{~h}$ after carrageenan administration), 
lung tissue sections were taken in order to determine the immunehistological staining for poly ADP-ribosylated proteins (an indicator of PARP activation). A positive staining for the PAR (Fig. 5F) was found primarily localized in the inflammatory cells present in the lung tissue from carrageenan-treated mice. 3,4-DHPEA-EA treatment reduced the degree of PARP activation (Fig. 5G). Please note that there was no staining for either nitrotyrosine (Fig. 5A) or PAR (Fig. 5E) in lung tissues obtained from the sham group of mice.
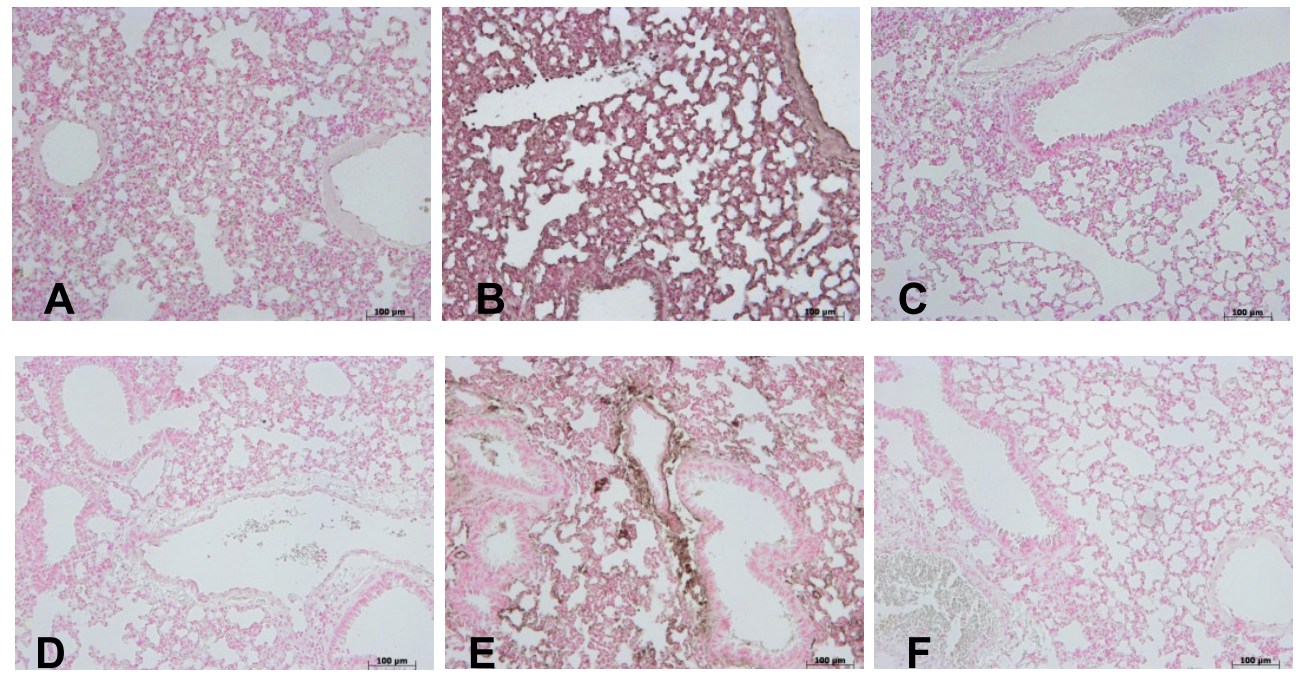

Figure 3. Effect of 3,4-DHPEA-EA (Ole aglycone) on the immunohistochemical localization of ICAM-1 and P-selectin in the lung after carrageenan injection. No positive staining for ICAM-1 was observed in lung sections taken from sham mice (A). Lung sections taken from carrageenan-treated mice showed intense positive staining for ICAM-1 along the vessels (B). The degree of positive staining for ICAM-1 was markedly reduced in lung sections obtained from mice treated with 3,4-DHPEA-EA (C). No positive staining for P-selectin was observed in lung sections taken from sham mice (D). Lung sections taken from carrageenan-treated mice treated with vehicle showed intense positive staining for Pselectin along the vessels (E). The degree of positive staining for P-selectin was markedly reduced in tissue sections obtained from mice treated with 3,4-DHPEA-EA (F). The figure is representative of at least three experiments performed on different experimental days. 

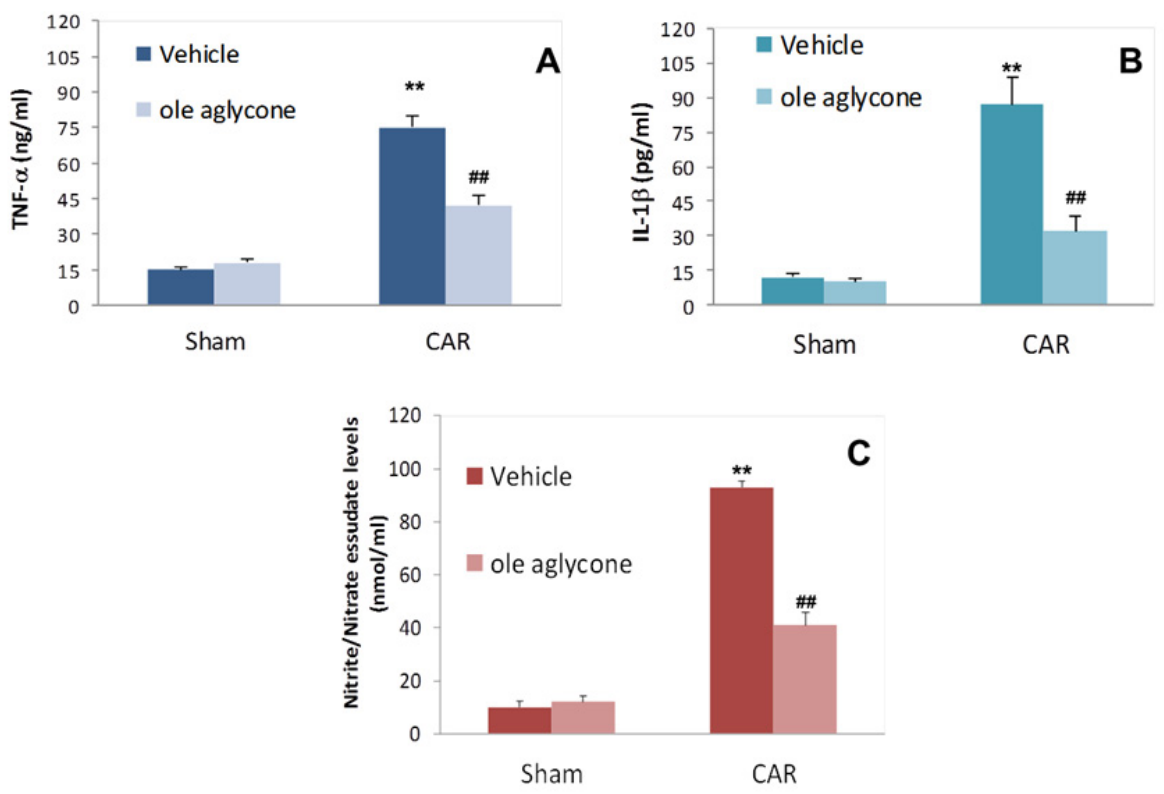

Figure 4. Effect of 3,4-DHPEA-EA (Ole aglycone) on carrageenan-induced pro-inflammatory cytokine release and NO formation in the lung. TNF- $\alpha$ and Il-1 $\beta$ levels were significantly elevated at $4 \mathrm{~h}$ after carrageenan administration in vehicle-treated mice (A and $B$ respectively), if compared with sham mice (A and B respectively). 3,4-DHPEA-EA significantly reduced TNF- $\alpha$ and Il-1 $\beta$ levels (A and B respectively). Moreover nitrite and nitrate levels, stable NO metabolites, were significantly increased in the pleural exudates at $4 \mathrm{~h}$ after carrageenan administration (C) if compared with sham mice (C). 3,4DHPEA-EA significantly reduced the carrageenan-induced elevation of nitrite and nitrate exudates levels $(\mathrm{C})$. Data are expressed as mean \pm S.E.M. from $\mathrm{n} 10$ mice for each group. ${ }^{* *}, \mathrm{P}<0.01$ versus sham group. $\#, \mathrm{P}<0.01$ versus carrageenan. 

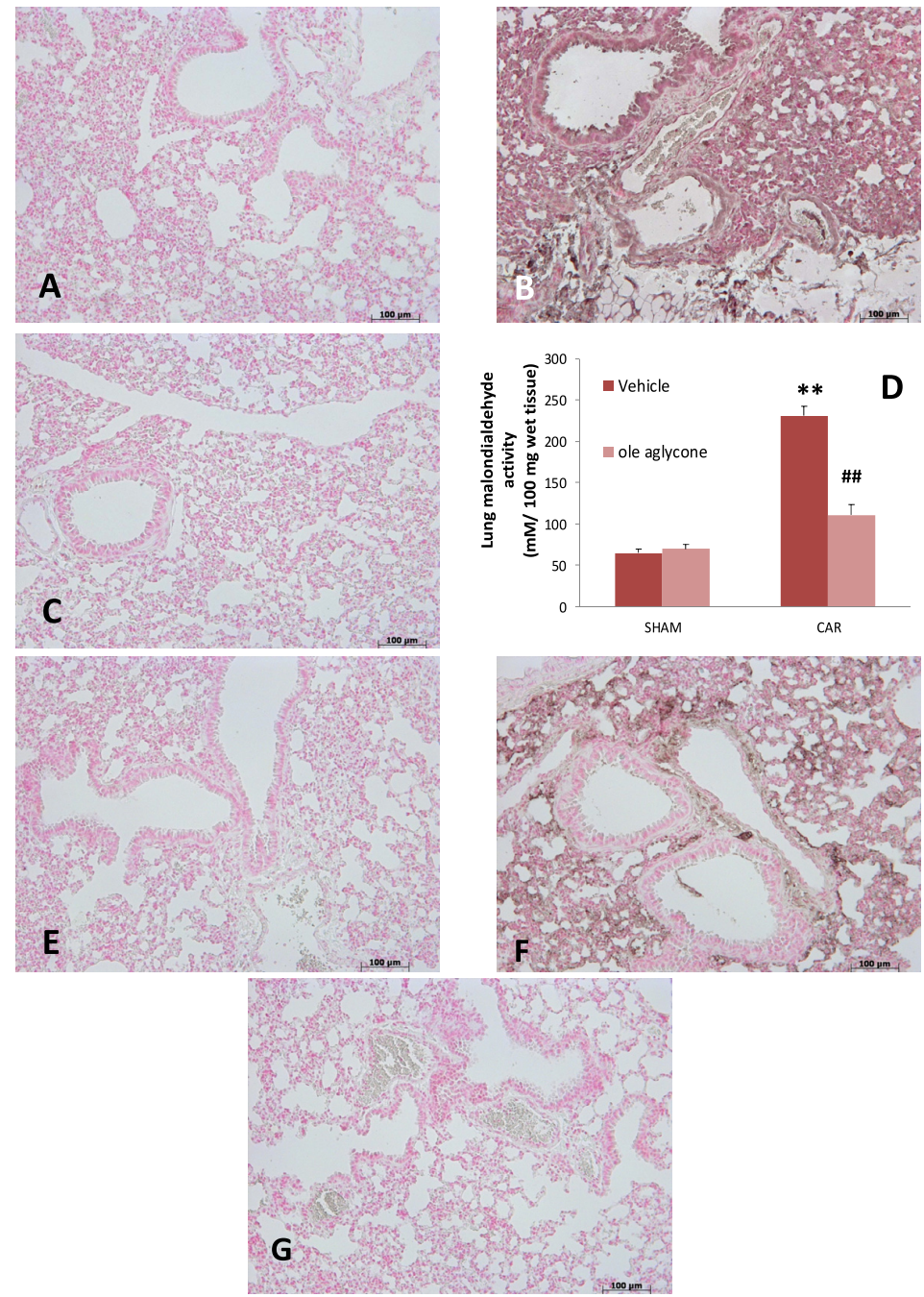

Figure 5. Effect of 3,4-DHPEA-EA (Ole aglycone) on carrageenan-induced nitrotyrosine formation, lipid peroxidation and PARP activation in the lung. No staining for nitrotyrosine is present in lung section from sham mice (A). Lung sections taken from carrageenan-treated mice treated with vehicle showed positive staining for nitrotyrosine, localized mainly in inflammatory cells (B). There was a marked reduction in the immunostaining for nitrotyrosine in the lungs of carrageenan-treated mice treated with 3,4-DHPEA-EA (C). Malondialdehyde (MDA) levels, an index of lipid peroxidation, were significantly increased in lung tissues $4 \mathrm{~h}$ after carrageenan administration (D), if compared with lung from sham mice (D). 3,4-DHPEAEA significantly reduced the carrageenan-induced elevation of MDA tissues levels (D). Lung sections taken from carrageenan-treated mice showed positive staining for PAR (F). There was a marked reduction in the immunostaining for PAR in the lungs of carrageenan-treated mice treated with 3,4-DHPEA-EA (G). Lung section from sham mice showed no staining for PAR (E). The figure is representative of at least 3 experiments performed on different experimental days. Data are expressed as mean \pm S.E.M. from $\mathrm{n} 10$ mice for each group. ${ }^{* *}, \mathrm{P}<0.01$ versus sham group. ${ }^{\sharp \#}, \mathrm{P}<0.01$ versus carrageenan. 


\subsection{Discussion}

All of the above findings are in support of the view that 3,4-DHPEA-EA attenuates the degree of acute inflammation in the mouse. What, then, is the mechanism by which ole reduces acute inflammation? One consequence of increased oxidative stress is the activation and inactivation of redox-sensitive proteins (Bowie \& O'Neill, 2000). Recent studies have observed that the acute consumption of olive oil decreased the activation of NF- $\kappa$ B system on mononuclear cells from healthy men (Perez-Martinez et al., 2007) and that 3,4-DHPEA-EA, trans-resveratrol, and hydroxytyrosol incubated with human umbilical vein endothelial cells inhibit LPS-triggered NF- $\kappa B$ and AP-1 activation (Carluccio et al., 2003). Moreover, various experimental evidence have clearly suggested that NF- $\kappa \mathrm{B}$ plays a central role in the regulation of many genes responsible for the generation of mediators or proteins in acute lung inflammation associated with carrageenan administration (Cuzzocrea et al., 2006) such us TNF- $\alpha$, IL-1 $\beta$, nitric oxide synthase inducible (iNOS) and COX-2. By inhibiting the activation of NF- $\kappa \mathrm{B}$, the production of joint destructive inflammatory mediators may be reduced as well. In this regard, Miles et al., demonstrated that ole glycoside significantly decreased the concentration of IL- $1 \beta$ in LPSstimulated human whole blood cultures. Therefore, this study also demonstrates that 3,4DHPEA-EA attenuates the TNF- $\alpha$ and IL-1 $\beta$ production in the lung of carrageenan-treated mice. In addition, recent studies also showed that the potential cardioprotective activity of oleuropein in acute cardiotoxicity induced by doxorubicin treatment was determined in vivo in rats (Andreadou et al., 2007) by inhibiting lipid peroxidation products, decreasing oxidative stress and reducing iNOS in cardiomyocytes. We show here that NO levels, evaluated as $\mathrm{NO}_{2} / \mathrm{NO}_{3}$ and MDA levels which is the products of lipid peroxidation, were increased at $4 \mathrm{~h}$ after carrageenan injection while 3,4-DHPEA-EA decreased the levels of NO and MDA. For many years, much attention has been paid to the effects of NO in respiratory diseases 26 but recently, the focus has been shifted toward RNS in general, and to peroxynitrite $\left(\mathrm{ONOO}^{-}\right)$in particular (Sadeghi-Hashjin et al., 1998). To probe the pathological contributions of $\mathrm{ONOO}^{-}$to acute lung injury we have used the appearance of nitrotyrosine staining in the inflamed tissue. We have observed here that the immunoassaying of nitrotyrosine is reduced in the lung of carrageenan-treated mice and treated with 3,4-DHPEA-EA. Therefore, the inhibition of nitrotyrosine formation by oleuropein described in the present study is most likely attributed to the strong antioxidant activity of ole. During inflammation initiation, circulating leukocytes must first be able to adhere selectively and efficiently to vascular endothelium. This process is facilitated by induction of vascular cell adhesion molecules on the inflamed endothelium, such as vascular cell adhesion molecule VCAM-1, ICAM-1, E-selectin demonstrated that 3,4DHPEA-EA was a more potent inhibitor of adhesion molecule expression on cultured human endothelial cells than was the glycoside(Carluccio et al., 2003). Furthermore, the absence of an increased expression of the adhesion molecule in the lung from CAR mice treated with 3,4DHPEA-EA was correlated with the reduction of leukocyte infiltration as assessed by the specific granulocyte enzyme MPO and with the attenuation of the lung tissue damage as evaluated by histological examination. Several studies also showed that in the auricular edema induced by either arachidonic acid (AA) or 12-O-tetradecanoylphorbol acetate (TPA), the topical application of the olive oil compounds such as ole also produced an inhibition of the 
MPO in the inflamed tissue (de la Puerta et al., 2000). Various studies have demonstrated that PARP activation after single DNA strand breakage induced by ROS plays an important role in the process of acute lung injury (Szabo et al., 1998). In this study we confirm the increase in PAR formation in the lung tissues from carrageenan-treated mice as well as that 3,4-DHPEAEA treatment attenuates PARP activation. In this regard, several studies demonstrated that hydroxytyrosol, a hydrolysis product of 3,4-DHPEA-EA, also exerts an inhibitory effect on peroxynitrite-dependent DNA base modifications and tyrosine nitration (Deiana et al., 1999). Similarly, Salvini et al. (2006) showed a 30\% reduction of oxidative DNA damage in peripheral blood lymphocytes during intervention on postmenopausal women with virgin olive oil containing high amounts of phenols. In conclusion, concomitant with inflammation is the generation of free radicals, which increase oxidation of proteins and lipids, resulting in signals that trigger more inflammation. Taken together, the results of the present study enhance our understanding of the role of ROS generation in the pathophysiology of carrageenan-induced pleurisy implying that olive oil compounds such as 3,4-DHPEA-EA may be useful in the therapy of acute inflammation.

\section{3,4-DHPEA-EA and chronic inflammation}

Premise - Reactive oxygen species (ROS) are produced in cells by several physiological and environmental stimulations, such as infections, ultraviolet radiation and pollutants, known collectively as oxidants. Interestingly, ROS have also been considered as risk and enhancer factors for autoimmune diseases (Filippin et al., 2008) as there is a significant relation between the oxidative stress and such diseases (Filippin et al., 2008; Avalos et al., 2007). Rheumatoid arthritis (RA) is an autoimmune disease characterized by the sequestration of various leukocyte subpopulations within both the developing pannus and synovial space. The chronic nature of this disease results in multiple joint inflammation with subsequent destruction of joint cartilage and erosion of bone. While this disease has a worldwide distribution, its pathogenesis is not clearly understood (Harris, 1990). Type II collageninduced arthritis (CIA) in the mouse has proven to be a useful model of RA, as it possesses many of the cell and humoral immunity characteristics found in human RA (Holmdahl et al., 1990). The pathogenesis of CIA is dependent upon the host's response to type II collagen challenge and the subsequent generation of antibodies that recognizes collagen rich joint tissue (Holmdahl et al., 1990). The chronic activities initiated by immune complexes trigger a variety of cell-mediated and humoral events. Moreover, the recruitment and activation of neutrophils, macrophages, and lymphocytes into joint tissues and the formation of the pannus are hallmarks of the pathogenesis of both CIA and human RA. Recently, it has been demonstrated that interleukin (IL)-8, macrophage inflammatory protein (MIP)-l $\alpha$, MIP-1 $\beta$, and RANTES are differentially chemotactic for lymphocyte subsets (Taub et al., 1993). Chemokines may play prominent roles in RA, as neutrophil and mononuclear cell stimulation and activation are prevalent in this disease. Concomitant with inflammation is the generation of ROS (Trichopoulou et al., 2003)which increase oxidation of proteins and lipids, resulting in signals that trigger more inflammation. Thus, the study model was designed to evaluate the effects of 3,4-DHPEA-EA in a mice model of chronic inflammation 
(development of CIA in the mice). We have evaluated the following endpoints of the inflammatory process: (1) clinical score; (2) body weight; (3) inducible oxide nitric synthase (iNOS) and cyclooxygenase expression (COX-2); (4) nitrotyrosine formation and activation of the nuclear enzyme poly (ADP-ribose) polymerase (PARP); (5) cytokine and chemokines production; (6) neutrophil infiltration; (7) joint histopathology.

Animals - DBA/1J mice (9 weeks, Harlan Nossan, Italy) were used for these studies. The animals were housed in a controlled environment and provided with standard rodent chow and water. Animal care was in compliance with Italian regulations on protection of animals used for experimental and other scientific purposes (Dlgs 116/92) as well as with the EEC regulations (O.J. of E.C. L 358/1 12/18/1986).

Experimental Design - Mice were divided into the following four experimental groups: (i) CIA-Control; mice were subjected to collagen-induced arthritis (as described below) and administered $200 \mu \mathrm{l}$ of $10 \%$ ethanol solution (i.p., vehicle for 3,4-DHPEA-EA) every $24 \mathrm{~h}$, starting from day 25 ( $\mathrm{n}=20$ ); (ii) CIA-3,4-DHPEA-EA; mice subjected to collagen-induced arthritis (as described below) were administered 3,4-DHPEA-EA (40 $\mu \mathrm{M} / \mathrm{kg}$, i.p.) every $24 \mathrm{~h}$, starting from day $25(\mathrm{n}=20)$; (iii) Sham-Control; mice subjected to an intradermal injection at the base of the tail of $100 \mu \mathrm{l}$ of $0.01 \mathrm{M}$ acetic acid instead of the emulsion containing 100 $\mu \mathrm{g}$ of CII, were treated with $200 \mu \mathrm{l}$ of $10 \%$ ethanol solution (i.p., vehicle for 3,4-DHPEA-EA), every $24 \mathrm{~h}$ starting from day $25(\mathrm{n}=20)$; (iv) Sham-3,4-DHPEA-EA; mice subjected to an intradermal injection at the base of the tail of $100 \mu \mathrm{l}$ of $0.01 \mathrm{M}$ acetic acid instead of the emulsion containing $100 \mu \mathrm{g}$ of CII, were administered 3,4-DHPEA-EA (40 $\mu \mathrm{M} / \mathrm{kg}$, i.p.), every $24 \mathrm{~h}$ starting from day $25(\mathrm{n}=20)$. The dose of 3,4-DHPEA-EA used here to reduce joint injury was chosen based on a previous study (Procopio A, et al., 2009). Collageninduced arthritis (CIA) is induced in mice by two consecutive (interval 21 days) intradermal injection of $100 \mu \mathrm{l}$ of the emulsion (containing $100 \mu \mathrm{g}$ of bovine type II collagen) (CII) and complete Freund's adjuvant (CFA) at the base of the tail. Mice develop erosive hind paw arthritis with macroscopic clinical evidence of CIA as peri-articular erythema and edema in the hind paws. The incidence of CIA is $100 \%$ by day 27 in the CII challenged and the severity of CIA progressed over a 35-day period with a reabsorption of bone. The histopathology of CIA include erosion of the cartilage at the joint.

Induction of CIA - Bovine CII was dissolved in $0.01 \mathrm{M}$ acetic acid at a concentration of 2 $\mathrm{mg} / \mathrm{ml}$ by stirring overnight at $4^{\circ} \mathrm{C}$. Dissolved $\mathrm{CII}$ was frozen at $-70^{\circ} \mathrm{C}$ until use. Complete Freund's adjuvant (CFA) was prepared by addition of Mycobacterium tuberculosis H37Ra at a concentration of $5 \mathrm{mg} / \mathrm{ml}$. Before injection, CII was emulsified with an equal volume of CFA. CIA was induced as previously described (Szabo et al., 1998). On day 1, mice were injected intradermally at the base of the tail with $100 \mu \mathrm{l}$ of the emulsion containing $100 \mu \mathrm{g}$ of CII. On day 21, a second injection of CII in CFA was administered.

Clinical assessment of CIA - The development of arthritis in mice in all experimental groups was evaluated daily starting from day 20 after the first intradermal injection by using a macroscopic scoring system: $0=$ no signs of arthritis; $1=$ swelling and/or redness of the paw or one digit; 2 = two joints involved; 3 = more than two joints involved; and 4 = severe arthritis of 
the entire paw and digits (Szabo et al., 1998). Arthritic index for each mouse was calculated by adding the four scores of individual paws. Clinical severity was also determined by quantitating the change in the paw volume using plethysmometry (model 7140; Ugo Basile).

Histological examination - On day 35, animals were sacrificed while they were under anesthesia (sodium pentobarbital, $45 \mathrm{mg} / \mathrm{kg}$, i.p), and paws and knees were removed and fixed in $10 \%$ formalin. The paws were then trimmed, placed in decalcifying solution for 24 $\mathrm{h}$, embedded in paraffin, sectioned at $5 \mu \mathrm{m}$, stained with hematoxylin/eosin and Masson's trichrome stain and studied using light microscopy (Dialux 22 Leitz).

Immunohistochemical localization of nitrotyrosine, Poly ADP Ribose (PAR), iNOS, and COX-2 - On day 35, the joints were trimmed, placed in decalcifying solution for $24 \mathrm{~h}$ and $8 \mu \mathrm{m}$ sections were prepared from paraffin embedded tissues. After deparaffinization, endogenous peroxidase was quenched with $0.3 \% \mathrm{H}_{2} \mathrm{O}_{2}$ in $60 \%$ methanol for $30 \mathrm{~min}$. The sections were permeabilized with $0.1 \%$ Triton X-100 in PBS for $20 \mathrm{~min}$. Non-specific adsorption was minimized by incubating the section in $2 \%$ normal goat serum in phosphate buffered saline for $20 \mathrm{~min}$. Endogenous biotin or avidin binding sites were blocked by sequential incubation for $15 \mathrm{~min}$ with avidin and biotin. Sections were incubated overnight with 1) anti-rabbit polyclonal antibody directed at iNOS (1:1000 in PBS, v/v) (DBA, Milan, Italy) or 2) anti-COX-2 goat polyclonal antibody (1:500 in PBS, v/v) or 3) anti- nitrotyrosine rabbit polyclonal antibody (1:1000 in PBS, v/v) or 4) with anti-PAR goat polyclonal antibody rat (1:500 in PBS, v/v) or 5). Controls included buffer alone or non-specific purified rabbit IgG. Specific labeling was detected with a biotin-conjugated goat anti-rabbit IgG (for nitrotyrosine and iNOS) or with a biotin-conjugated goat anti-rabbit IgG (for PAR and COX-2) and avidin-biotin peroxidase complex. In order to confirm that the immunoreaction for the nitrotyrosine was specific some sections were also incubated with the primary antibody (anti-nitrotyrosine) in the presence of excess nitrotyrosine $(10 \mathrm{mM})$ to verify the binding specificity. To verify the binding specificity for PAR, COX-2 and iNOS, some sections were also incubated with only the primary antibody (no secondary) or with only the secondary antibody (no primary). In these situations, no positive staining was found in the sections indicating that the immunoreaction was positive in all the experiments carried out. Immunocytochemistry photographs $(\mathrm{N}=5)$ were assessed by densitometry by using Optilab Graftek software on a Macintosh personal computer.

Measurement of cytokines - Tumor Necrosis Factor- $\alpha$ (TNF- $\alpha$ ) levels were evaluated in the plasma from CIA and sham mice as previously described (Cuzzocrea et al., 2006). The assay was carried out using a colorimetric commercial ELISA kit (Calbiochem-Novabiochem Co., Milan, Italy) with a lower detection limit of $10 \mathrm{pg} / \mathrm{ml}$.

Measurement of chemokines - Levels of chemokines MIP-1 $\alpha$ and MIP-2 were measured in the aqueous joint extracts. Briefly, joint tissues were prepared by first removing the skin and separating the limb below the ankle joint. Joint tissues were homogenized on ice in $3 \mathrm{ml}$ lysis buffer (PBS containing: $2 \mathrm{mM}$ PMSF, and 0,1 mg/ml [final concentration], each of aprotinin, antipain, leupeptin, and pepstatin A) using Polytron (Brinkinarm Instr., Westbury, NY). The homogenized tissues were then centrifuged at 2,000 g for $10 \mathrm{~min}$. Supernatant were sterilized with a millipore filter $(0.2 \mu \mathrm{m})$ and stored at $-80^{\circ} \mathrm{C}$ until 
analyzed. The extracts usually contained $0.2-1.5 \mathrm{mg}$ protein $/ \mathrm{ml}$, as measured by protein assay kit (Pierce Chemical Co., Rockford, IL). The levels of MIP-1 $\alpha$ and MIP-2 were quantified using a modification of a double ligand method, as previously described (Kasama et al., 1994). Briefly, flat-bottomed 96- well microtiter plates were coated with 50 $\mu \mathrm{l} /$ well of rabbit anti-cytokine antibodies $\left(1 \mu \mathrm{g} / \mathrm{ml}\right.$ in $0.6 \mathrm{~mol} / \mathrm{liter} \mathrm{NaCl}, 0.26 \mathrm{~mol} / \mathrm{liter} \mathrm{H}_{3} \mathrm{BO}_{4}$ and $0.08 \mathrm{~N} \mathrm{NaOH}, \mathrm{pH} 9.6$ ) for $16 \mathrm{~h}$ at $4^{\circ} \mathrm{C}$, and then washed with PBS, $\mathrm{pH} 7.5,0.05 \%$ Tween 20 (wash buffer). Nonspecific binding sites on microtiter plates were blocked with $2 \%$ BSA in PBS and incubated for $90 \mathrm{~min}$ at $37^{\circ} \mathrm{C}$. Plates were rinsed four times with wash buffer, and diluted aqueous joint samples $(50 \mu \mathrm{l})$ were added, followed by incubation for $1 \mathrm{~h}$ at $37^{\circ} \mathrm{C}$. After washing of plates, chromogen substrate was added. The plates were incubated at room temperature to the desired extinction, after which the reaction was terminated with $50 \mu \mathrm{l} /$ well of $3 \mathrm{M} \mathrm{H}_{2} \mathrm{SO}_{4}$ solution. The plates were then read at $490 \mathrm{~nm}$ in an ELISA reader. This ELISA method consistently had a sensitivity limit of $\sim 30 \mathrm{pg} / \mathrm{ml}$.

Myeloperoxidase (MPO) assay - Neutrophil infiltration to the inflamed joints was indirectly quantitated using an MPO assay, as previously described for neutrophil elicitation (Mullane et al., 1985). Tissue was prepared as described above and placed in a $50 \mathrm{mM}$ phosphate buffer ( $\mathrm{pH}=6.0$ ) with $5 \%$ hexadecyltrimethyl ammonium bromide (Sigma Chemical Co.). Joint tissues were homogenized, sonicated, and centrifuged at $12,000 \mathrm{~g}$ for $15 \mathrm{~min}$ at $4^{\circ} \mathrm{C}$. Supernatants were assayed for MPO activity using a spectrophotometric reaction with Odianisidine hydrochloride (Sigma Chemical Co.) at $460 \mathrm{~nm}$.

Materials - 3,4-DHPEA-EA was obtained from Merck Biosciences (Calbiochem, Beecham, Nottingham, UK). Unless otherwise stated, other compounds were obtained from SigmaAldrich Company (Milan, Italy). All chemicals were of the highest commercial grade available. All stock solutions were prepared in nonpyrogenic saline $(0.9 \% \mathrm{NaCl}$; Baxter Healthcare Ltd., Thetford, Norfolk, U.K.) or 10\% ethanol (Sigma-Aldrich).

Data analysis - All values in the figures and text are expressed as mean \pm standard error (s.e.m.) of the mean of $\mathrm{n}$ observations. For the in vivo studies $n$ represents the number of animals studied. In the experiments involving histology or immunohistochemistry, the figures shown are representative of at least three experiments (histological or immunohistochemistry coloration) performed on different experimental days on the tissue sections collected from all the animals in each group. Data sets were examined by one- or two-way analysis of variance, and individual group means were then compared with Student's unpaired $t$ test. For the arthritis studies, Mann-Whitney $U$ test (two-tailed, independent) was used to compare medians of the arthritic indices (Szabo et al., 1998). A pvalue of less than 0.05 was considered significant.

\subsection{Results}

Effect of 3,4-DHPEA-EA on joint injury during experimental arthritis - To imitate the clinical scenario of RA, mice were subjected to CIA. CIA developed rapidly in mice immunized with $\mathrm{CII}$ and clinical signs (periarticular erythema and edema) (Fig. 6B) of the disease first appeared in hind paws between 24 and 26 days post-challenge (Fig. 6D) leading to a 100\% incidence of 
CIA at day 28 (Fig. 6D). Hind paw erythema and swelling increased in frequency and severity in a time-dependent mode with maximum arthritis indices of approximately 10 observed between day 29 to 35 post immunization (Fig. 6D) in CIA-control mice. 3,4-DHPEA-EA treatment demonstrated a significant reduction of joint inflammation, as identified by a significant reduction in the incidence of arthritis (Figure 6C). CIA-3,4-DHPEA-EA mice showed a $40 \%$ reduction in the development of arthritis and a significantly lower arthritis index compared to CIA- control mice (Fig. 6D). There was no macroscopic evidence of either hind paw erythema or edema in the sham-control group mice (Fig. 6A and D). The data in Figure $6 \mathrm{E}$ demonstrate a time-dependent increase in hind paw volume (each value represents the mean of both hind paws). The CIA-3,4-DHPEA-EA mice showed a significant reduction of paw edema formation when compared to CIA-control mice (Fig. 6E). No increase in hind paw volume over time was observed in the sham-control mice (Fig. 6E). The rate and the absolute gain in body weight were comparable in sham-control and CIA-control mice in the first week (Fig. 6F). From day 25, the CII-challenged mice gained significantly less weight than the shamcontrol mice, and this trend continued through to day 35. 3,4-DHPEA-EA treatment determined a significant increase of the weight gain compared with the vehicle-treatment in CIA-control mice (Fig. 6F). The histological evaluation (on day 35) of the joint from CIAcontrol mice (Fig. 7B) revealed signs of severe arthritis, with inflammatory cell infiltration and bone erosion. The histological alterations of joint were significantly reduced in 3,4-DHPEAEA-treated mice (Fig. 7C). Moreover Masson's trichrome stain reveals decreased collagen (blue stain) in bone and cartilage of arthritic joint due to bone erosion and cartilage degradation in CIA-control mice (Fig. 7E). The alterations of joint were significantly reduced in 3,4-DHPEAEA-treated mice (Fig. 7F). There was no evidence of pathology in the sham-control mice (Fig. 7A and D). The histological score (Fig. 7G) was determined by an independent observer.

Effect of 3,4-DHPEA-EA on cytokines, chemokine expression and neutrophil infiltration - We initiated studies to assess the effect of 3,4-DHPEA-EA on the expression of chemokines in the aqueous joint extracts during the development of CIA. As shown in Fig. 8, A and B, the expression of MIP- $1 \alpha$ and MIP-2, measured by ELISA, was significantly increased in the joint 35 days after CII immunization. MIP-1 $\alpha$ and MIP-2 levels in CIA-3,4-DHPEA-EA mice on day 35 were significantly reduced in a dose-dependent manner in comparison with those in vehicle treated CIA-control mice. Assessment of neutrophil infiltration into the inflamed joint tissue was performed by measuring the activity of MPO. It was significantly elevated 35 days after CII immunization in vehicle-treated CIA-control mice (Fig. 8F), whereas in the CIA-3,4-DHPEAEA group, MPO activity was markedly reduced in a dose-dependent manner (Fig. 8F). To test whether 3,4-DHPEA-EA modulates the inflammatory process through the regulation of cytokine secretion, we analyzed the plasma levels of the proinflammatory cytokines TNF- $\alpha$, IL-1 $\beta$, and IL-6. A substantial increase in TNF- $\alpha$, (Fig. 8C), IL-1 $\beta$ (Fig. 8D), and IL-6 (Fig. 8E) production was found in CIA-control mice 35 days after CII immunization. Levels of TNF- $\alpha$ (Fig. 8C), IL-1 $\beta$ (Fig. 8D), and IL-6 (Fig. 8E) were significantly reduced in a dose-dependent manner in CIA-3,4-DHPEA-EA mice in comparison to CIA-control mice.

Effect of 3,4-DHPEA-EA treatment on iNOS, COX-2, PGE2, nitrotyrosine, and PAR formation Immunohistochemical analysis of the tibiotarsal joint sections obtained from CIA-control 
mice revealed positive staining for iNOS (Fig. 10, A and A1) and COX-2 (Fig. 9, A and A1), which were primarily localized in inflammatory cells. In contrast, staining for iNOS (Fig. 10B) and COX-2 (Fig. 9B) was markedly reduced in the tibiotarsal joints of CIA-3,4-DHPEAEA $(40 \mu \mathrm{g} / \mathrm{kg})$ mice. No staining for either iNOS or COX-2 was detected in the tibiotarsal joints obtained from sham control mice (data not shown). Moreover, we also evaluated the
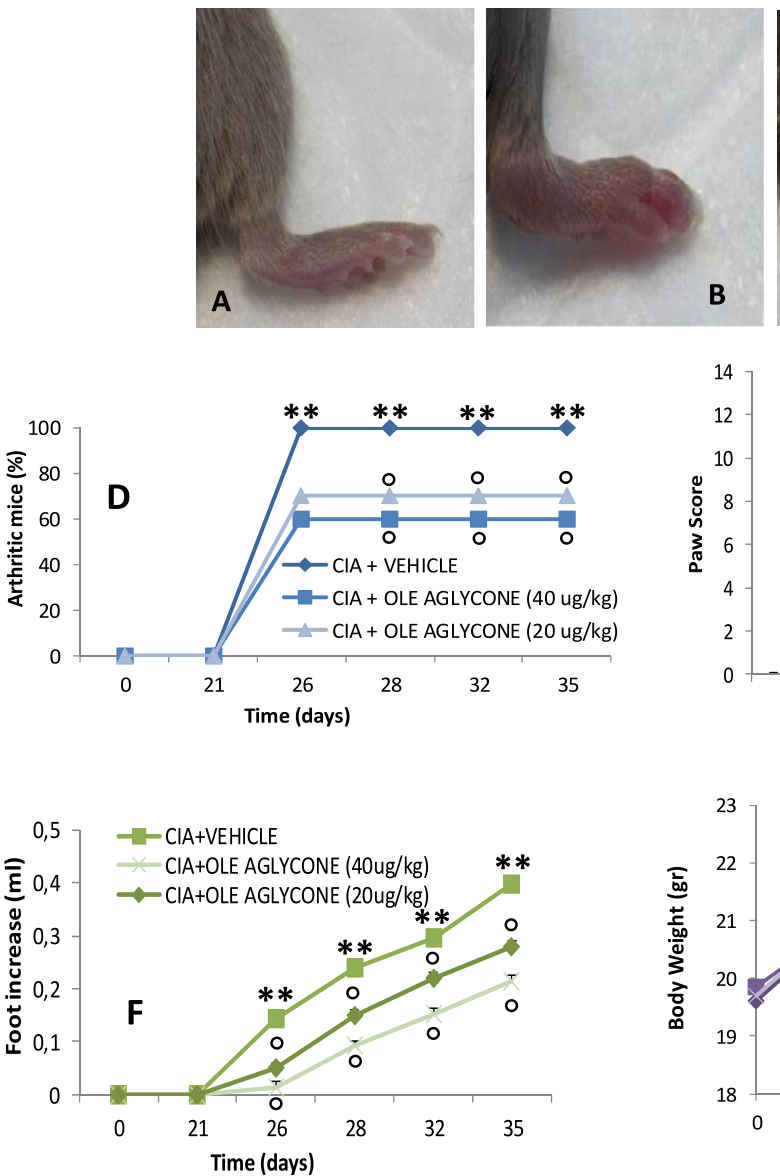
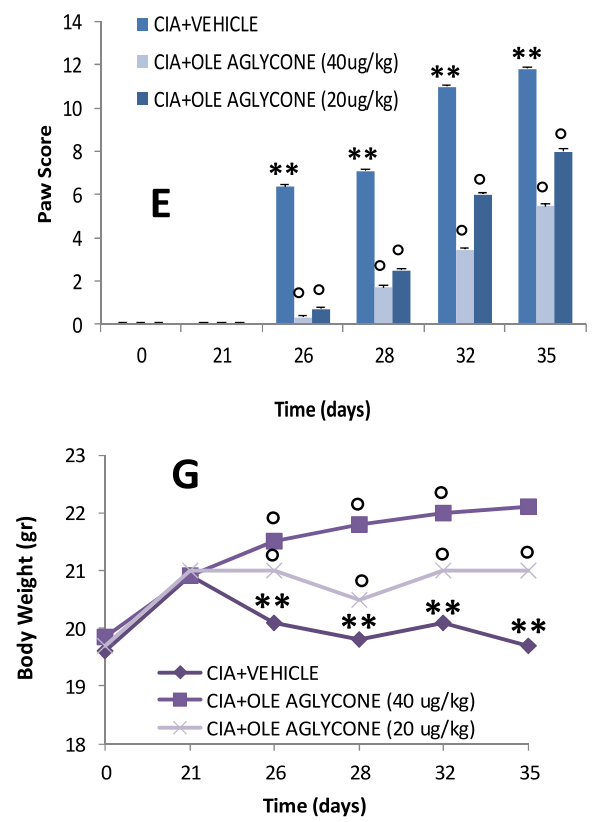

Figure 6. Effect of 3,4-DHPEA-EA (Ole aglycone) on the clinical expression of CIA and on body weight. $A$, no clinical signs were observed in sham mice. CIA developed rapidly in mice immunized with CII and clinical signs such as periarticular erythema and edema (B) were seen with a $100 \%$ incidence of CIA at day 28 (D). E, hind paw erythema and swelling increased in frequency and severity in a time dependent mode. CIA-3,4-DHPEA-EA mice demonstrated a significant reduction in the clinical signs of CIA (C), leading to a decrease in the incidence of arthritis in a dose-dependent manner (D). Swelling of hind paws (F) over time was measured at 2-day intervals. G, beginning on day 25, the CII-challenged mice gained significantly less weight and this trend continued through day 35. CIA-3,4-DHPEA-EA mice demonstrated a significant reduced incidence of weight loss $(\mathrm{G})$ as well as less paw edema in a dose dependent manner $(\mathrm{F})$. The figure is representative of all the animals in each group. Values are means \pm S.E.M. of 20 animals for each group. ${ }^{* *}, \mathrm{P}<0.01$ versus sham-control; ${ }^{\circ}, \mathrm{P}<0.01$ versus CIA. 

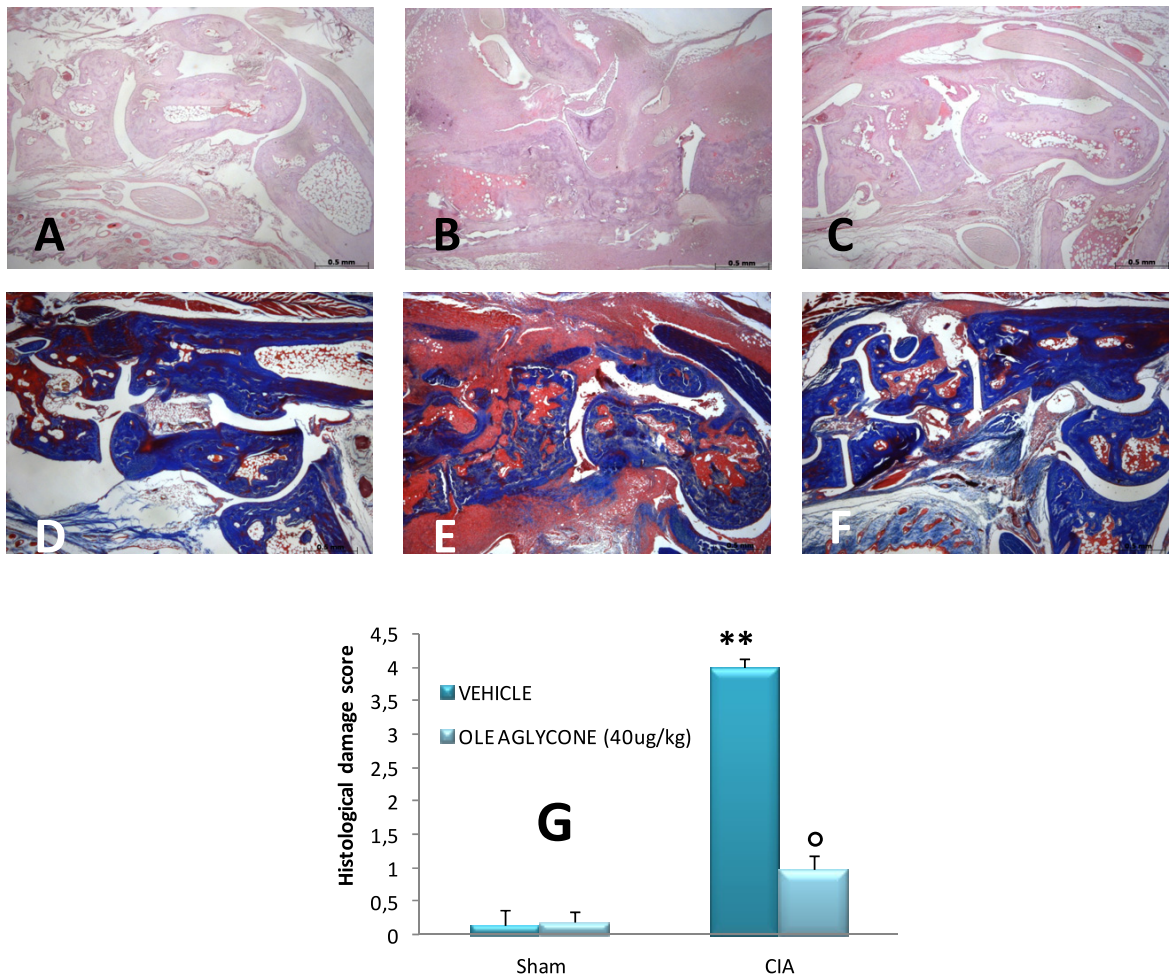

Figure 7. Morphological changes of CIA. Representative hematoxylin and eosin-stained section of joint was examined by light microscopy. The histological evaluation (on day 35) of joint from CIA-control mice (B and G) revealed signs of severe arthritis, with inflammatory cell infiltration and bone erosion. The histological alterations of the joint were significantly reduced in the tissues from CIA-3,4-DHPEAEA (40 $\mu \mathrm{g} / \mathrm{kg}$ )-treated mice (C and G). Masson's trichrome stain reveals decreased collagen in bone and cartilage of arthritic joint due to bone erosion and cartilage degradation in CIA-control mice (E and G). The alterations of joint were significantly reduced in 3,4-DHPEA-EA $(40 \mu \mathrm{g} / \mathrm{kg})$-treated mice (F and $\mathrm{G})$. There was no evidence of pathology in the sham-control mice (A, D, and $G$ ). The histological score $(G)$ was made by an independent observer. The figure is representative of at least three experiments performed on different experimental days. Values are means \pm S.E.M. of 20 animals for each group. ${ }^{* *}, \mathrm{P}$ $<0.01$ versus sham-control; ${ }^{\circ}, \mathrm{P}<0.01$ versus $\mathrm{CIA}$.

levels of PGE2, the metabolite of COX-2, in the serum during the development of CIA. A substantial increase in $\mathrm{PGE}_{2}$ production was found in CIA-control mice 35 days after $\mathrm{CII}$ immunization (Fig. 9E). Levels of PGE-2 were significantly reduced in CIA-3,4-DHPEA-EA mice in a dose dependent manner compared with those in CIA-control mice (Fig. 9E). The release of free radicals and oxidant molecules during chronic inflammation has been suggested to contribute significantly to the tissue injury (Cuzzocrea et al., 2001). On day 35, positive staining for nitrotyrosine, a marker of nitrosative injury, was found in the tibiotarsal joints of vehicle-treated CIA-control mice (Fig. 11, A and A1). 3,4-DHPEA-EA (40 $\mu \mathrm{g} / \mathrm{kg}$ ) treatment significantly reduced the formation of nitrotyrosine (Fig. 11B). Immunohistochemical analysis of joint sections obtained from CII-challenged mice revealed 
positive staining for PAR (Fig. 12, A and A1). In contrast, no positive PAR was found in the tibiotarsal joints of CII-challenged mice treated with 3,4-DHPEA-EA (40 $\mu \mathrm{g} / \mathrm{kg})$ (Fig. 12B). There was no staining for either nitrotyrosine or PAR in the tibiotarsal joints obtained from sham-control mice (data not shown).
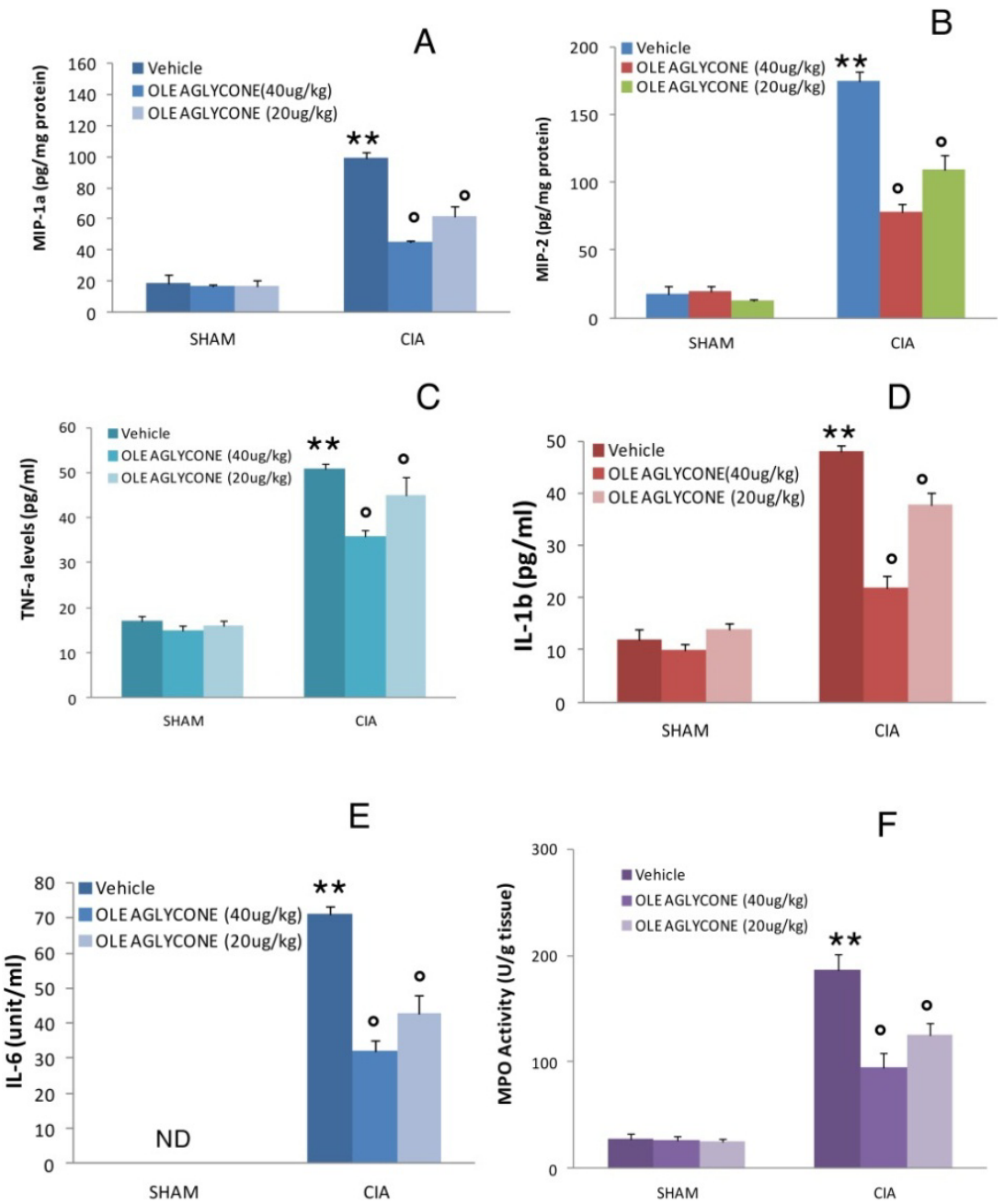

Figure 8. Effect of 3,4-DHPEA-EA (Ole aglycone) treatment on cytokine and chemokine expression and neutrophil infiltration. A substantial increase in the expression of MIP-1 (A), MIP-2 (B), MPO activity $(\mathrm{F})$, plasma TNF- $\alpha(\mathrm{C}), \mathrm{IL}-1 \beta$ (D), and IL-6 levels (E) was found in CIA-control mice 35 days after CII immunization. CIA-3,4-DHPEA-EA mice demonstrated a significant reduction in the expression of MIP-1 (A), MIP-2 (B), MPO activity (F), plasma TNF- $\alpha$ (C), IL-1 $\beta$ (D), and IL-6 levels in a dose dependent manner (E). Values are means \pm S.E.M. of 20 animals for each group. ${ }^{* *}, \mathrm{P}<0.01$ versus sham control; ${ }^{\circ}, \mathrm{P}<0.01$ versus CIA-control. ND, not detectable. 

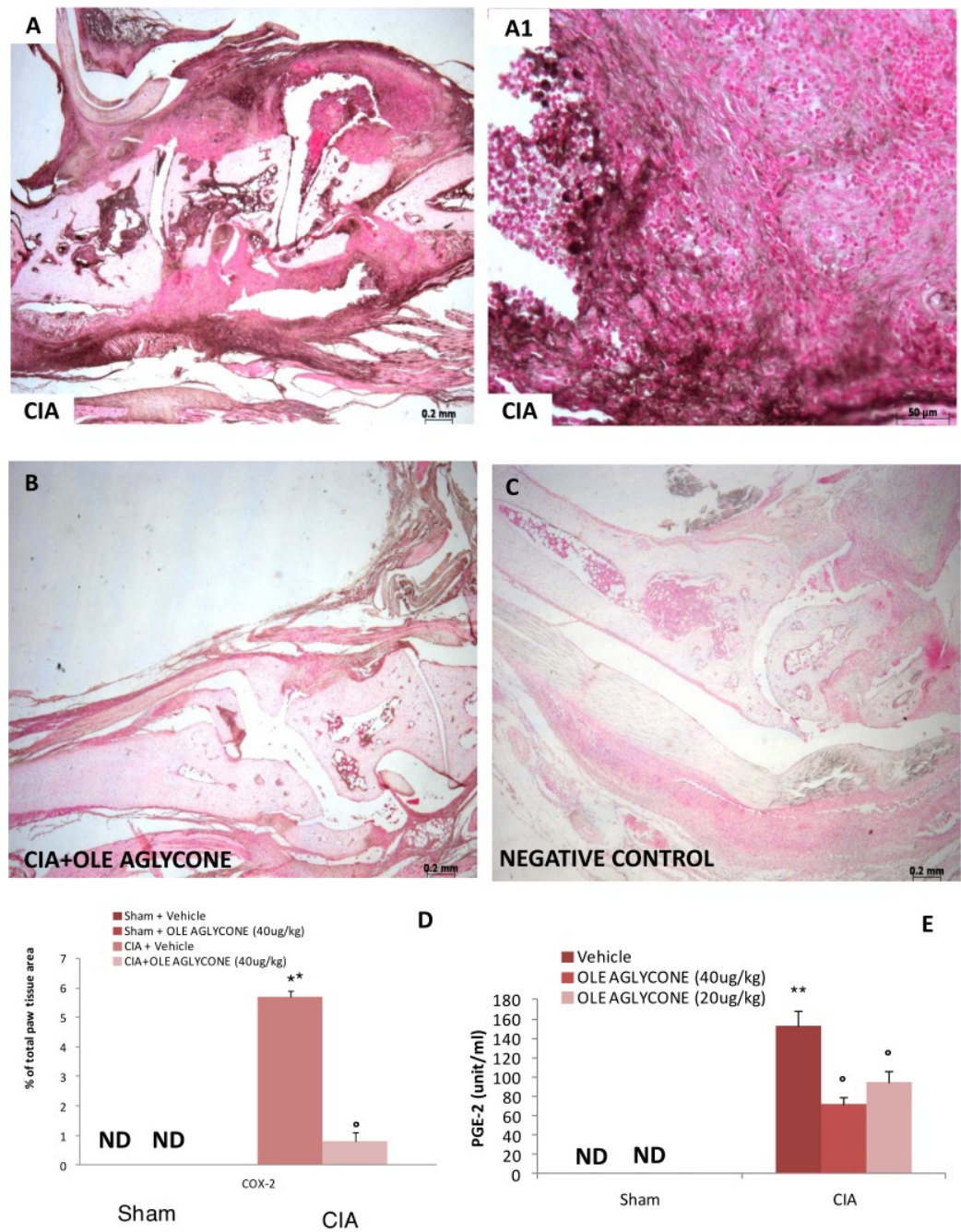

Figure 9. Effect of 3,4-DHPEA-EA (Ole aglycone) treatment on COX-2 immunostaining and on serum PGE2 levels. A marked increase in COX-2 (A and in particular A1) staining was evident in the paw 35 days after initiation of CIA. There was a marked reduction in the immunostaining for COX-2 (B) in the paw of CIA-3,4DHPEA-EA $(40 \mu \mathrm{g} / \mathrm{kg})$ mice. To verify the binding specificity for COX-2, some sections were also incubated with only the secondary antibody (no primary antibody). No positive staining for COX-2 was found in the sections indicating that the immunoreaction was positive (see negative control C). In addition, a marked increase of PGE2 levels was found in the serum of CIA control mice 35 days after CII immunization (E). The treatment with 3,4-DHPEA-EA also caused a significant reduction in a dose-dependent manner of the serum levels of the metabolite of COX-2 (E). The figure is representative of at least three experiments performed on different experimental days. Densitometry analysis of immunocytochemistry photographs $(n=5)$ for COX-2 from paw section was assessed (D). The assay was performed by using Optilab Graftek software on a Macintosh personal computer (CPU G3-266). Data are expressed as a percentage of total tissue area. ${ }^{* *}, \mathrm{P}<$ 0.01 versus sham control; ${ }^{\circ}, \mathrm{P}<0.01$ versus $\mathrm{CIA}$. ND, not detectable. 

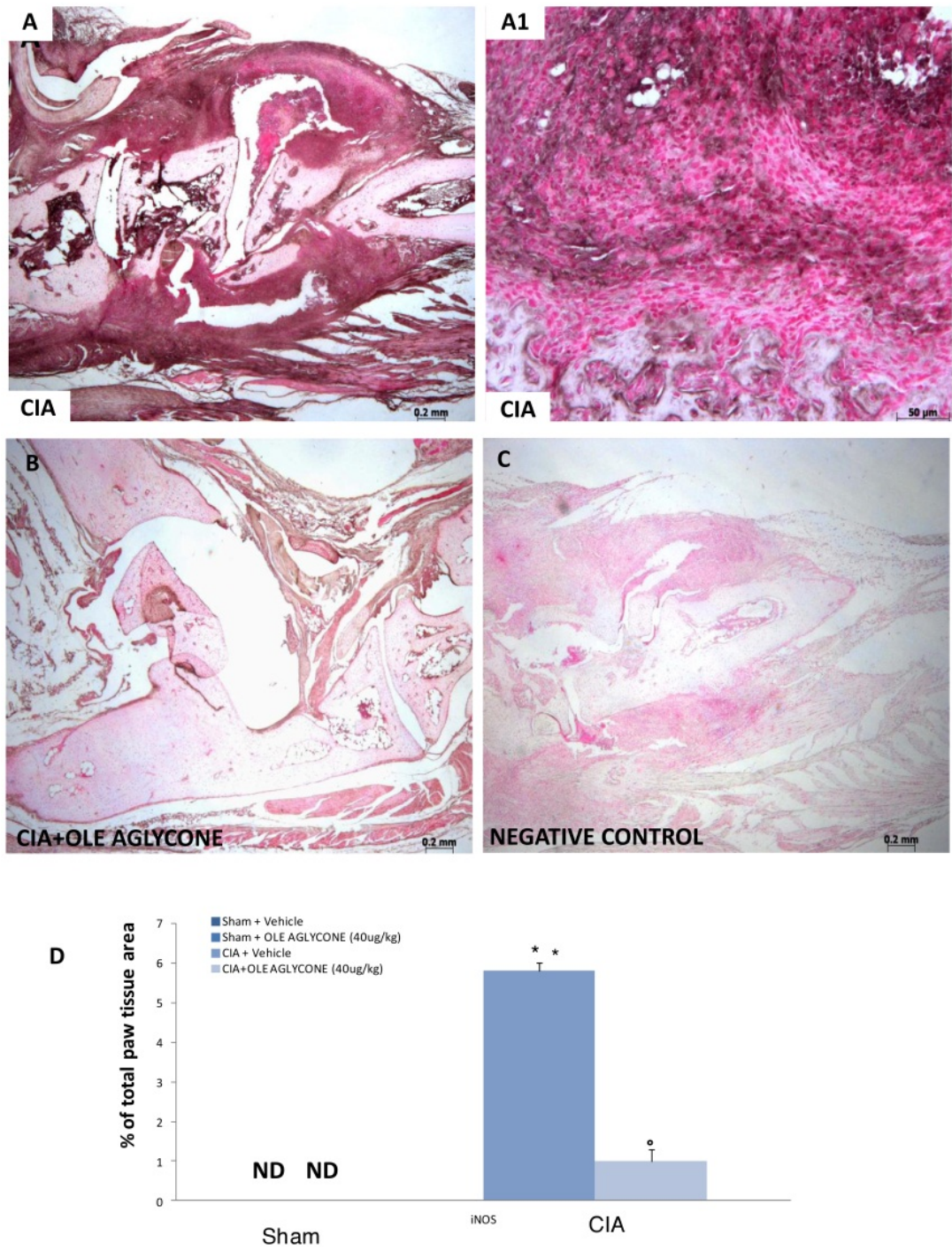

Figure 10. Effect of 3,4-DHPEA-EA (Ole aglycone) treatment on iNOS immunostaining. A marked increase in iNOS (A and in particular A1) staining was evident in the paw 35 days after initiation of CIA. There was a marked reduction in the immunostaining for iNOS (B) in the paw of CIA-3,4-DHPEAEA $(40 \mu \mathrm{g} / \mathrm{kg})$ mice. To verify the binding specificity for iNOS, some sections were also incubated with only the secondary antibody (no primary antibody). No positive staining for iNOS was found in the sections, indicating that the immunoreaction was positive (see negative control C). The figure is representative of at least three experiments performed on different experimental days. Densitometry analysis of immunocytochemistry photographs $(n=5)$ for iNOS from paw section was assessed (D). The assay was performed by using Optilab Graftek software on a Macintosh personal computer (CPU G3266). Data are expressed as a percentage of total tissue area. ${ }^{* *}, \mathrm{P}<0.01$ versus sham-control; ${ }^{\circ}, \mathrm{P}<0.01$ versus CIA. ND, not detectable. 

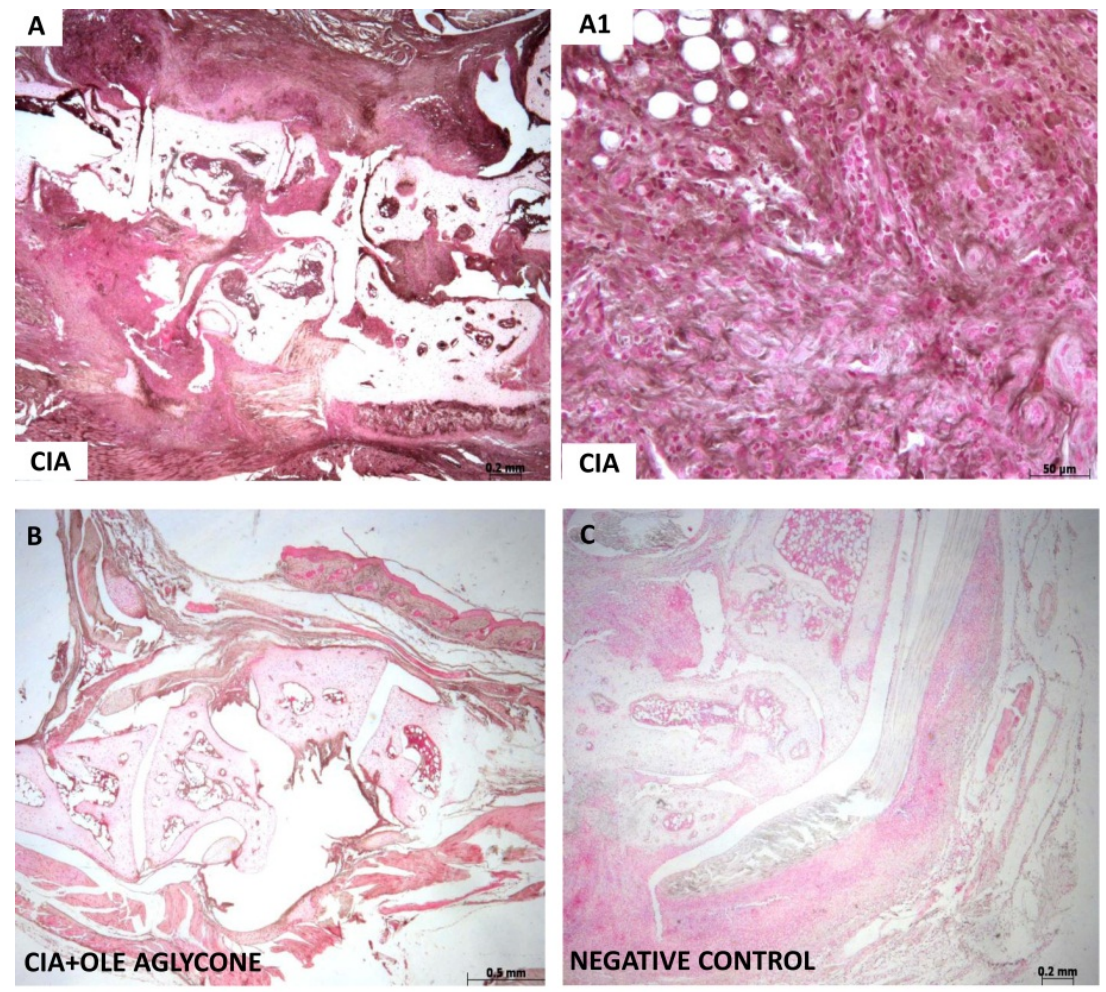

D

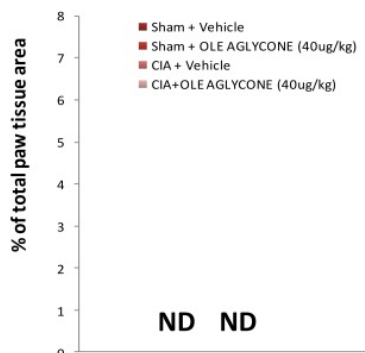

Sham

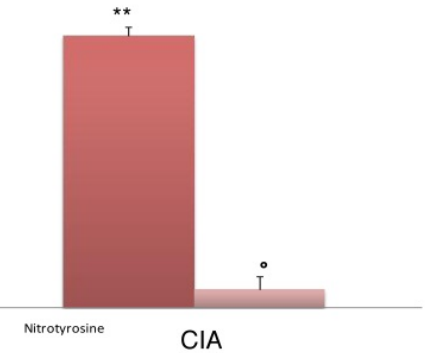

Figure 11. Effect of 3,4-DHPEA-EA (Ole aglycone) treatment on nitrotyrosine immunostaining. A marked increase in nitrotyrosine (A and in particular A1) staining was evident in the paw 35 days after initiation of CIA. There was a marked reduction in the immunostaining for nitrotyrosine (B) in the paw of CIA-3,4-DHPEA-EA (40 $\mu \mathrm{g} / \mathrm{kg}$ )-treated mice. To verify the binding specificity for nitrotyrosine, some sections were also incubated with only the secondary antibody (no primary antibody). No positive staining for nitrotyrosine was found in the sections, indicating that the immunoreaction was positive (see negative control C). The figure is representative of at least three experiments performed on different experimental days. Densitometry analysis of immunocytochemistry photographs $(n=5)$ for nitrotyrosine from paw section was assessed (D). The assay was performed by using Optilab Graftek software on a Macintosh personal computer (CPU G3-266). Data are expressed as a percentage of total tissue area. ${ }^{* *}, \mathrm{P}<0.01$ versus sham control; ${ }^{\circ}, \mathrm{P}<0.01$ versus $\mathrm{CIA}$. ND, not detectable. 

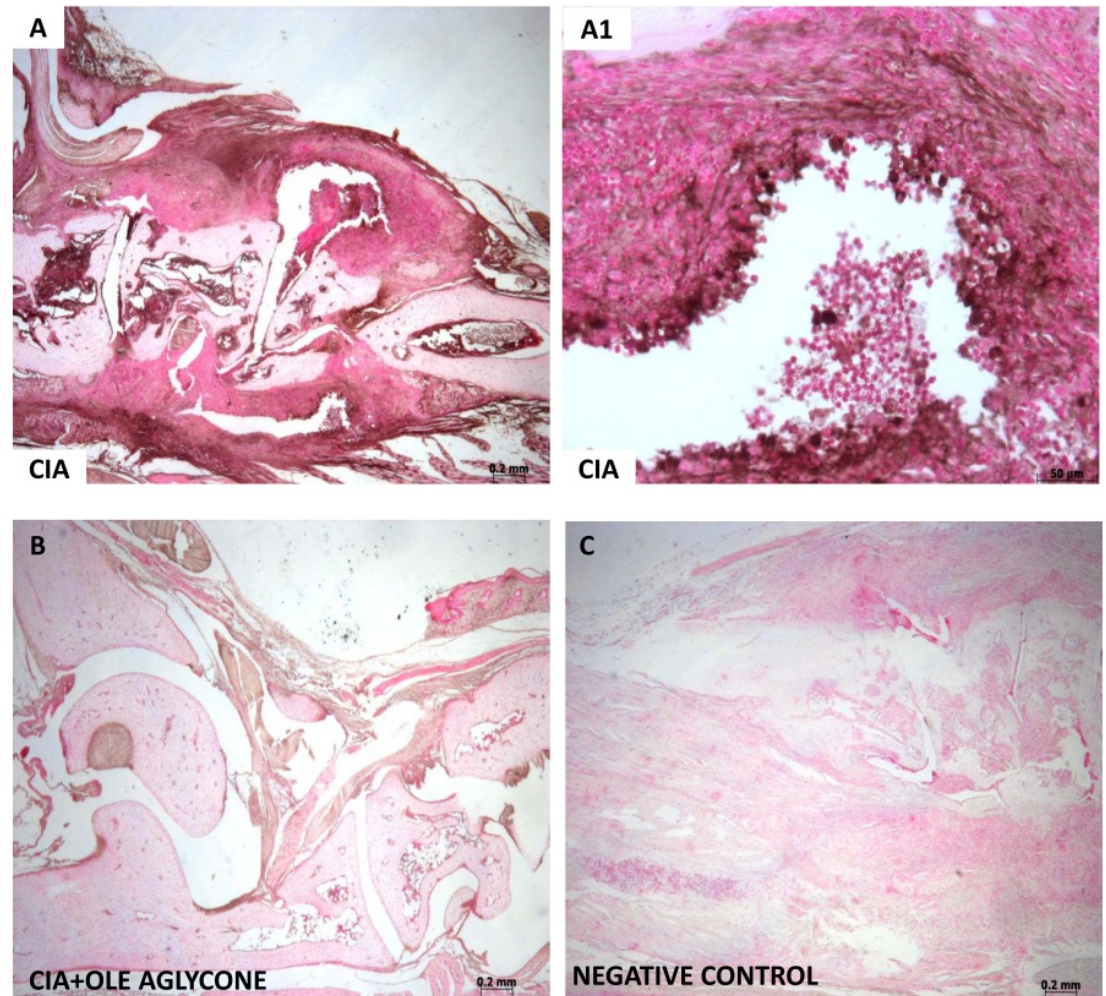

D

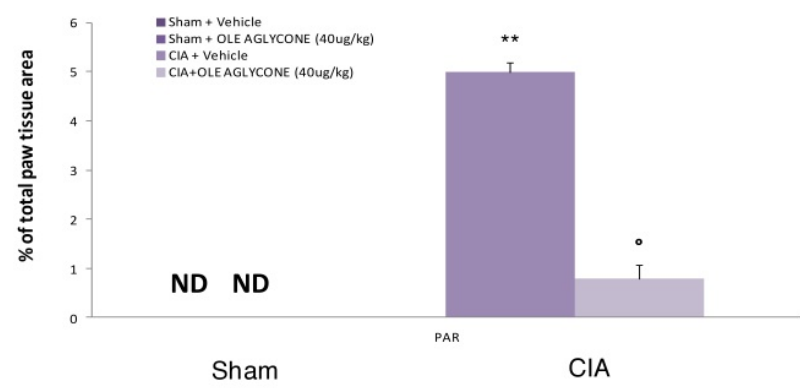

Figure 12. Effect of 3,4-DHPEA-EA (Ole aglycone) treatment on PARP immunostaining. A marked increase in PARP (A and in particular A1), staining was evident in the paw 35 days after initiation of CIA. There was a marked reduction in the immunostaining for PARP (B) in the paw of CIA-3,4DHPEA-EA ( $40 \mu \mathrm{g} / \mathrm{kg}$ )-treated mice. To verify the binding specificity for PARP, some sections were also incubated with only the secondary antibody (no primary antibody). No positive staining for PARP was found in the sections, indicating that the immunoreaction was positive (see negative control C). The figure is representative of at least three experiments performed on different experimental days.

Densitometry analysis of immunocytochemistry photographs $(n=5)$ for PARP from paw section was assessed (D). The assay was performed by using Optilab Graftek software on a Macintosh personal computer (CPU G3-266). Data are expressed as a percentage of total tissue area. ${ }^{* *}, \mathrm{P}<0.01$ versus shamcontrol; ${ }^{\circ}, \mathrm{P}<0.01$ versus $\mathrm{CIA}$. ND, not detectable. 
3,4-DHPEA-EA Inhibits the Progression of Established Arthritis - To confirm that 3,4DHPEA-EA exerts beneficial effects in the experimental model of collagen-induced arthritis, we have also evaluated its effect in a therapeutic regimen of post-treatment $(40 \mu \mathrm{g} / \mathrm{kg})$, starting the treatment at day 28. CIA-3,4-DHPEA-EA post-treatment mice also showed a reduction in the development of arthritis and a significantly lower arthritis score compared with those in CIA-control mice as shown in Fig. 13A. 3,4-DHPEA-EA post-treatment also significantly reduced paw edema formation (Fig. 13B). In addition, 3,4-DHPEA-EA posttreated mice showed significantly reduced histological alterations of the tibiotarsal joint as shown in the histological score (Fig. 13C) and increased body weight (Fig. 13D).

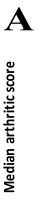

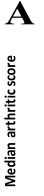

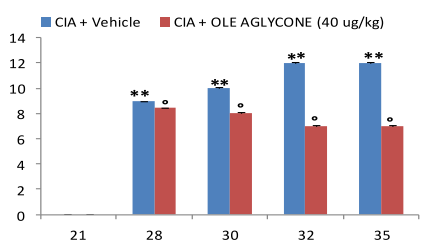

C

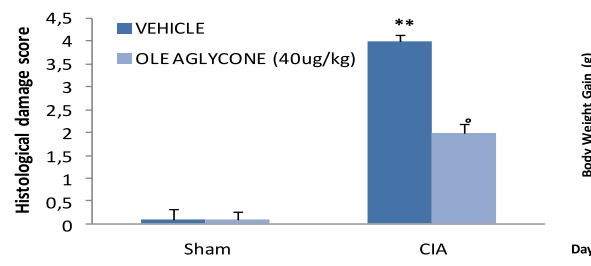

B

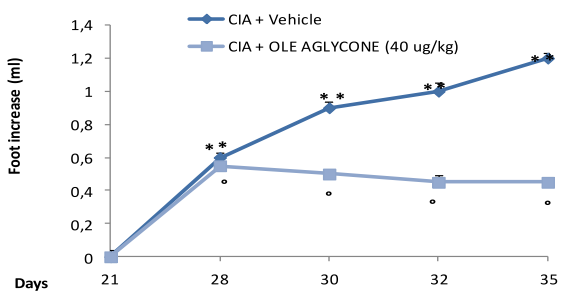

D

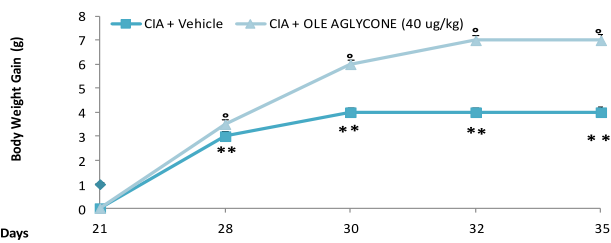

Figure 13. Effect of 3,4-DHPEA-EA (Ole aglycone) post-treatment on joint inflammation. Starting the treatment at day 28 , we have also demonstrated that 3,4-DHPEA-EA post-treatment $(40 \mu \mathrm{g} / \mathrm{kg})$ caused a significantly lower arthritis score (A) and a reduction of foot increase (B) compared with the CIAcontrol. In addition, we have also shown a reduction in the histological damage (C) and increased body weight (D) in 3,4-DHPEA-EA -treated mice. Data are expressed as a percentage of total tissue area. ${ }^{* *}$, $P<0.01$ versus sham-control; ${ }^{\circ}, P<0.01$ versus CIA.

\subsection{Discussion}

Rheumatoid arthritis is an inflammatory disease characterized by chronic inflammation of the synovial joints associated with proliferation of synovial cells and infiltration of activated immunoinflammatory cells, including memory $\mathrm{T}$ cells, macrophages, and plasma cells, leading to progressive destruction of cartilage and bone (Hitchon et al., 2004). Another central feature of RA synovitis is the transformation of fibroblast-like synovial cells into autonomously proliferating cells with a tissue-infiltrating nature, forming hyperplastic 
tissue with the potential for bone erosion and cartilage degradation known as pannus (Filippin et al., 2008). Therefore, it is necessary to establish and characterize experimental animal models to assess cellular and molecular events that contribute to the pathogenesis of joint inflammation. Of interest, CII-induced arthritis in the mouse has proven to be a useful model, because it possesses many of the cellular and humoral immune events found in human rheumatoid arthritis. Oxidative stress describes an imbalance between ROS synthesis and antioxidants. Many studies have demonstrated a role of ROS in the pathogenesis of inflammatory chronic arthropathies, such as rheumatoid arthritis (Filippin et al., 2008). In this regard, we investigate here the effects of 3,4-DHPEA-EA, a hydrolysis product of oleuropein, in a mouse model of CII-induced arthritis. Although T-cell and antibody responses against CII are a crucial event for the initiation of CIA (Holmdahl et al., 1989), it has been demonstrated that several cytokines also appear to direct cell-to-cell communication in a cascade fashion during the progression of CIA such as IL-1 (Hom et al., 1992), TNF- $\alpha$ (Dong et al., 2010), and IL-6 (Ferraccioli et al., 2010). In addition, it has been demonstrated that monocyte chemotactic protein-1, MIP- $\alpha$, MIP-1 $\beta$, and regulated on activation normal $\mathrm{T}$ cell expressed and secreted are differentially chemotactic for lymphocyte subsets and are expressed in tissue from the inflamed joints of patients with rheumatoid arthritis (Koch et al., 1994). In this study, we have confirmed that the cytokines (TNF- $\alpha$, IL-1 $\beta$, and IL-6) as well as the chemokines (MIP- $1 \alpha$ and MIP-2) are expressed at sites of inflamed joints and probably contribute in different capacities to the progression of chronic joint inflammation. Several cytokines, including TNF- $\alpha$ and IL-1 $\beta$, are known initiators of the nuclear factor (NF- $\kappa$ B) activation cascade (Filippin et al., 2008) and are under its transcriptional control, constituting a positive feedback loop. Recent studies have observed that the acute consumption of olive oil decreased the activation of the NF- $\kappa B$ system on mononuclear cells from healthy men (Perez-Martinez et al., 2007) and that 3,4DHPEA-EA, trans-resveratrol, and hydroxytyrosol incubated with human umbilical vein endothelial cells inhibit lipopolysaccharide-triggered NF- $\kappa B$ and activator protein-1 activation (Carluccio et al., 2003). Of interest, using 3,4-DHPEA-EA, we have demonstrated an inhibition of the release of proinflammatory cytokines and chemokines and a reduction of leukocyte infiltration measured by MPO activity. Several studies also showed that the potential cardioprotective activity of oleuropein in acute cardiotoxicity induced by doxorubicin treatment was determined in vivo in rats (Andreadou et al., 2007) by inhibiting lipid peroxidation products, decreasing oxidative stress, and reducing iNOS in cardiomyocytes and that the olive oil polyphenols are capable of down-regulating COX-2 expression in colonic cancer cells by a mechanism involving the early inhibition of p38 mitogen-activated protein kinase and downstream inhibition of the transcription factor cAMP response element-binding protein (Corona et al., 2007). We show here that 3,4DHPEA-EA decreased iNOS and COX-2 expression by immunohistochemical staining and also reduced the levels of the metabolite of COX-2, PGE2, in the serum of 3,4-DHPEA-EA treated mice. Reactive nitrogen species, such as the peroxynitrite radical (ONOO-) generated by the reaction between $\mathrm{O} 2$. and nitric oxide, can also cause oxidative damage (Soneja et al., 2005). The addition of ONOO- to body cells, tissues, and fluids leads to fast protonation, which may result in the depletion of $-\mathrm{SH}$ groups and other antioxidants, oxidation and 
nitration of lipids, DNA disruption, and nitration and deamination of DNA bases (Filippin et al., 2008). In this report, an intense immunostaining of nitrotyrosine formation also suggested that a structural alteration of joint had occurred, most probably due to the formation of highly reactive nitrogen derivatives ROS produce strand breaks in DNA, which triggers energy-consuming DNA repair mechanisms and activates the nuclear enzyme poly(ADP-ribosyl) polymerase (PARP). There is various evidence that the activation of PARP may also play an important role in inflammation (Genovese et al., 2005). Continuous or excessive activation of PARP produces extended chains of ADP-ribose (PAR) on nuclear proteins and results in a substantial depletion of intracellular NAD and subsequently, ATP, leading to cellular dysfunction and, ultimately, cell death (Chiarugi, 2002). We demonstrate here that 3,4-DHPEA-EA treatment reduced the activation of PARP with a decrease in PAR expression in the joint during CIA. In this regard, several studies demonstrated that hydroxytyrosol, a hydrolysis product of 3,4-DHPEA-EA, also exerts an inhibitory effect on peroxynitrite-dependent DNA base modifications and tyrosine nitration (Deiana et al., 1999). Likewise, Salvini et al. (2006) showed a 30\% reduction of oxidative DNA damage in peripheral blood lymphocytes during intervention in postmenopausal women with virgin olive oil containing high amounts of phenols. Thus, 3,4-DHPEA-EA, given at the onset of the disease, reduced paw swelling, clinical score, and the histological severity of the disease when injected after the onset of clinical arthritis. Amelioration of joint disease was associated with near to full inhibition of cytokines as well as inhibition of neutrophil infiltration, which is a key player in RA. Therefore, 3,4-DHPEA-EA was also administered from day 28 after collagen immunization, targeting this early initiation phase of CIA. Then, with treatment starting at day 28, 3,4-DHPEA-EA post-treatment caused a significant reduction of inflamed joints collected at day 35. In conclusion, RA is a complex chronic inflammatory disease dependent on multiple interacting environmental and genetic factors, making it difficult to understand its pathogenesis and thereby to find effective therapies. Taken together, the results of the present study enhance our understanding of the role of ROS generation in the pathophysiology of CII-induced arthritis, implying that olive oil compounds such as 3,4-DHPEA-EA may be useful in the therapy of inflammation.

\section{Overall conclusion}

Oxidative stress is described as an imbalance between ROS synthesis and antioxidant system in the mammal body where the normal production of oxidants is counteracted by several antioxidative mechanisms. Food constituents are the normal substrate for energy generation but a hypercaloric diet may result in higher ROS, thus inducing oxidative stress. Epidemiological studies have shown that populations consuming a predominantly olive oilbased Mediterranean-style diet exhibit lower incidences of breast cancer and other chronic diseases than those eating a northern European or North American diet. Habitual high intakes of olive oil, especially virgin olive oil, provide a continuous supply of antioxidants, which may reduce oxidative stress via inhibition of lipid peroxidation, a factor that is currently linked to a host of diseases such as cancer, heart disease, and ageing. 


\section{Author details}

Domenico Britti and Antonio Procopio

Dept. of Health Sciences, University of Catanzaro, Catanzaro, Italy

Daniela Impellizzeri and Salvatore Cuzzocrea

Dept. of Clinical and Experimental Medicine and Pharmacology, University of Messina, Torre Biologica - Policlinico Universitario, Messina, Italy

\section{References}

Andreadou I, Sigala F, Iliodromitis EK, Papaefthimiou M, Sigalas C, Aligiannis N, Savvari P, Gorgoulis V, Papalabros E, Kremastinos DT. Acute doxorubicin cardiotoxicity is successfully treated with the phytochemical oleuropein through suppression of oxidative and nitrosative stress. J Mol Cell Cardiol 2007;42:549-558.

Angerosa F, d'Alessandro N, Corana F, Mellero G. Characterization of phenolic and secoiridoids aglycones present in virgin olive oil. J Chromatogr 1996; 736: 195-203.

Artajo LS, Romero MP, Morello JR, Motilva MJ. Enrichment of refined olive oil with phenolic compounds: evaluation of their antioxidant activity and their effect on the bitter index. J Agric Food Chem. 2006; 54: 6079-6088.

Avalos I, Chung CP, Oeser A, Milne GL, Morrow JD, Gebretsadik T, Shintani A, Yu C, Stein $\mathrm{CM}$ : Oxidative stress in systemic lupus erythematosus: relationship to disease activity and symptoms. Lupus 2007, 16:195-200.

Bendini A, Cerratani L, Carasco-Pancorbo A, Gomez-Caravaca AM, Segura-Carretero A, Fernandez-Gutierrez A, Lerker G. Phenolic molecules in virgin olive oils: a survey of their sensory properties, health effects, antioxidant activity and analytical methods. An overview of the last decade. Molecules 2007, 12: 1679-1719.

Bowie A, O'Neill LA. Oxidative stress and nuclear factor-kappaB activation: a reassessment of the evidence in the light of recent discoveries. Biochem Pharmacol 2000;59:13-23.

Carasco-Pancorbo A, Cerratani L, Bendini A, Segura-Carretero A, Del Carlo M, GallinaToschi T, Lerker G, Compagnoni D, Fernandez-Gutierrez A. Evaluation of the antioxidant capacity of individual phenolic compounds in virgin olive oil. J Agric Food Chem. 2005; 53: 8918-8925.

Carluccio M A, Siculella L, Ancora MA, Massaro M, Scoditti E, Storelli C, Visioli F, Distante A, De Caterina R. Olive oil and red wine antioxidant polyphenols inhibit endothelial activation: antiatherogenic properties of Mediterranean diet phytochemicals. Arterioscler Thromb Vasc Biol 2003; 23: 622-29.

Chen CC, Chow MP, Huang WC, Lin YC, Chang YJ. Flavonoids inhibit tumor necrosis factor-alpha-induced up-regulation of intercellular adhesion molecule-1 (ICAM-1) in respiratory epithelial cells through activator protein-1 and nuclear factor-kappaB: structure-activity relationships. Mol Pharmacol 2004; 66: 683-693. 
Chiarugi A. Poly(ADP-ribose) polymerase: killer or conspirator? The 'suicide hypothesis' revisited. Trends Pharmacol Sci 2002; 23:122-129.

Corona G, Deiana M, Incani A, Vauzour D, Dessi MA, Spencer JP. Inhibition of p38/CREB phosphorylation and COX-2 expression by olive oil polyphenols underlies their antiproliferative effects. Biochem Biophys Res Commun 2007, 362:606-611.

Covas MI. Bioactive effects of olive oil phenolic compounds in humans: reduction of heart disease factors and oxidative damage. Inflammopharmacology 2008; 16: 216-8

Cuzzocrea S, Crisafulli C, Mazzon E, Esposito E, Muià C, Abdelrahman M, Di Paola R, Thiemermann $C$. Inhibition of glycogen synthase kinase-3beta attenuates the development of carrageenan-induced lung injury in mice. Br J Pharmacol 2006; 149: 687702.

Cuzzocrea S, Riley D P, Caputi A P, Salvemini D. Antioxidant therapy: a new pharmacological approach in shock, inflammation, and ischemia/reperfusion injury. Pharmacol Rev 2001;53:135-159.

Cuzzocrea S, Sautebin L, De Sarro G, Costantino G, Rombolà L, Mazzon E, Ialenti A, De Sarro A, Ciliberto G, Di Rosa M, Caputi A P, Thiemermann C. Role of IL-6 in the pleurisy and lung injury caused by carrageenan. J Immunol 1999;163: 50945104.

de la Puerta R, Martinez-Dominguez E, Ruiz-Gutierrez V. Effect of minor components of virgin olive oil on topical antiinflammatory assays. Z Naturforsch C 2000; 55: 814-819.

Deiana M, Aruoma O I, Bianchi ML, Spencer JP, Kaur H, Halliwell B, Aeschbach R, Banni S, Dessi MA, Corongiu FP. Inhibition of peroxynitrite dependent DNA base modification and tyrosine nitration by the extra virgin olive oil-derived antioxidant hydroxytyrosol. Free Radic Biol Med 1999; 26: 762-9.

Della Ragione F, Cucciolla V, Borriello A, Della Pietra V, Pontoni G, Racioppi L, Manna C, Galletti P, Zappia V. Hydroxytyrosol, a natural molecule occurring in olive oil, induces cytochrome c-dependent apoptosis. Biophys Res Commun 2000; 278: 733-739.

Dong J, Gao Y, Liu Y, Shi J, Feng J, Li Z, Pan H, Xue Y, Liu C, Shen B et al: The protective antibodies induced by a novel epitope of human TNF-alpha could suppress the development of collagen-induced arthritis. PloS one 2010, 5:8920.

Esti M, Cinquanta L, La Notte E. Phenolic compounds in different olive varieties. J Agric Food Chem. 1998; 46: 32-35.

Fabiani R, De Bartolomeo A, Rosignoli P, Servili M, Montedoro GF, Morozzi G. Cancer chemoprevention by hydroxytyrosol isolated from virgin olive oil through $\mathrm{G} 1$ cell cycle arrest and apoptosis. Eur J Cancer Prev 2002; 11: 351-358.

Fabiani R, De Bartolomeo A, Rosignoli P, Servili M, Selvaggini R, Montedoro GF, Di Saverio C, Morozzi G. Virgin olive oil phenols inhibit proliferation of human promyelocytic leukemia cells (HL60) by inducing apoptosis and differentiation. J Nutr 2006; 136: 614619. 
Fabiani R, Rosignoli P, De Bartolomeo A, Fuccelli R, Servili M, Montedoro GF, Morozzi G. Oxidative DNA damage is prevented by extracts of olive oil, hydroxytyrosol, and other olive phenolic compounds in human blood mononuclear cells and HL60 cells. J Nutr 2008; 138: 1411-1426.

Ferraccioli G, Bracci-Laudiero L, Alivernini S, Gremese E, Tolusso B, De Benedetti F. Interleukin-1beta and Interleukin-6 in arthritis animal models. Roles in the early phase of transition from the acute to chronic inflammation and relevance for human rheumatoid arthritis. Mol Med 2010, 16: 552-7.

Fialkow L, Wang Y, Downey G P. Reactive oxygen and nitrogen species as signaling molecules regulating neutrophil function. Free RadicBiol Med 2007;42:153-164.

Filippin LI, Vercelino R, Marroni NP, Xavier RM: Redox signalling and the inflammatory response in rheumatoid arthritis. Clin Exp Immunol 2008, 152: 415-422.

Genovese T, Mazzon E, Muia' C, Patel NS, Threadgill MD, Bramanti P, De Sarro A, Thiemermann C, Cuzzocrea S. Inhibitors of poly(ADP-ribose) polymerase modulate signal transduction pathways and secondary damage in experimental spinal cord trauma. J Pharmacol ExpTher 2005; 312: 449-457.

Gutierrez-Rosales F, Rios JJ, Gomez-Rey ML. Main polyphenols in the bitter taste of virgin olive oil. Structural confirmation by on-line High-Performance Liquid Chromatography Electrospray Ionization Mass Spectrometry. J Agric Food Chem 2003; 51: 6021-6025.

Harris ED, Jr.: Rheumatoid arthritis. Pathophysiology and implications for therapy. N Engl J Med 1990, 322:1277-1289.

Hitchon CA, El-Gabalawy HS: Oxidation in rheumatoid arthritis. Arthritis Res Ther 2004, 6:265-278.

Holmdahl R, Andersson M, Goldschmidt TJ, Gustafsson K, Jansson L, Mo JA. Type II collagen autoimmunity in animals and provocations leading to arthritis. Immunol Rev 1990;118:193-232.

Holmdahl R, Mo J, Nordling C, Larsson P, Jansson L, Goldschmidt T, Andersson M, Klareskog L. Collagen induced arthritis: an experimental model for rheumatoid arthritis with involvement of both DTH and immune complex mediated mechanisms. Clin Exp Rheumatol 1989; 7: S51-55.

Hom JT, Cole H, Estridge T, Gliszczynski VL. Interleukin-1 enhances the development of type II collagen-induced arthritis only in susceptible and not in resistant mice. Clin Immunol Immunopathol 1992; 62: 56-65.

Impellizzeri D, Esposito E, Mazzon E, Paterniti I, Di Paola R, Bramanti P, Morittu VM, Procopio A, Britti D, Cuzzocrea S. The effects of oleuropein aglycone, an olive oil compound, in a mouse model of carrageenan-induced pleurisy. Clin Nutr 2011; 30: 53340.

Impellizzeri D, Esposito E, Mazzon E, Paterniti I, Di Paola R, Morittu VM, Procopio A, Britti $\mathrm{D}$, Cuzzocrea S. Oleuropein aglycone, an olive oil compound, ameliorates development 
of arthritis caused by injection of collagen type II in mice. J Pharmacol Exp Ther. 2011; 339: 859-69.

Kasama T, Strieter RM, Lukacs NW, Burdick MD, Kunkel SL: Regulation of neutrophilderived chemokine expression by IL-10. J Immunol 1994, 152:3559-69.

Koch AE, Kunkel SL, Harlow LA, Mazarakis DD, Haines GK, Burdick MD, Pope RM, Strieter RM: Macrophage inflammatory protein-1 alpha. A novel chemotactic cytokine for macrophages in rheumatoid arthritis. J Clin Invest 1994; 93:21-928.

Li JM, Gall NP, Grieve DJ, Chen M, Shah AM. Activation of NADPH oxidase during progression of cardiac hypertrophy to failure. Hypertension 2002; 40: 477-484.

Menendez JA, Vazquez-Martin A, Colomer R, Brunet J, Carrasco-Pancorbo A, GarciaVillalba R, Fernandez-Gutierrez A, Segura-Carretero A. Olive oil's bitter principle reverses acquired autoresistance to trastuzumab (Herceptin) in HER2-overexpressing breast cancer cells. BMC Cancer 2007;(7) 80.

Miles EA, Zoubouli P, Calder PC. Differential anti-inflammatory effects of phenolic compounds from extra virgin olive oil identified in human whole blood cultures. Nutrition 2005;21:389-394.

Montedoro GF, Servili M, Baldioli M, Miniati E. Simple and hydrolyzable phenolic compounds in virgin olive oil. 1. Initial characterization of the hydrolyzable fraction. J Agric Food Chem 1992; 40: 1571-1577; ibidem 1578-1580.

Mullane K M, Kraemer R, Smith B. Myeloperoxidase activity as a quantitative assessment of neutrophil infiltration into ischemic myocardium. J Pharmacol Methods 1985;14:157167.

Nantel F, Denis D, Gordon R, Northey A, Cirino M, Metters KM, Chan CC. Distribution and regulation of cyclooxygenase-2 in carrageenan-induced inflammation. Br J Pharmacol 1999;128: 853-9.

Ohkawa H, Ohishi N, Yagi K. Assay for lipid peroxides in animal tissues by thiobarbituric acid reaction. Anal Biochem 1979; 95: 351-358.

Omar SH. Oleuropein in olive and its pharmacological effects. Sci Pharm 2010; 78: 13354.

Owen RW, Mier W, Giacosa A, Hull WE, Spiegelhalder B, Bartsch H. Phenolic compounds and squalene in olive oils: the concentration and antioxidant potential of total phenols, simple phenols, secoiridoids, lignansand squalene. Food Chem Toxicol 2000; 38: 647659.

Paiva-Martins F, Fernandes J, Rocha S, Nascimento H, Vitorino R, Amado F, Borges F, Belo L, Santos-Silva A. Effects of olive oil polyphenols on erythrocyte oxidative damage. Mol Nutr Food Res. 2009; 53: 609-616.

Paiva-Martins F, Gordon MH. Isolation and characterization of the antioxidant component 3,4-dihydroxyphenylethyl 4-formyl-3-formylmethyl-4-hexenoate from olive (Olea europaea) leaves. J Agric Food Chem. 2001; 49: 4214-4219.

Perez-Martinez P, Lopez-Miranda J, Blanco-Colio L, Bellido C, Jimenez Y, Moreno JA, Delgado-Lista J, Egido J, Perez-Jimenez F. The chronic intake of a Mediterranean diet 
enriched in virgin olive oil, decreases nuclear transcription factor kappa B activation in peripheral blood mononuclear cells from healthy men. Atherosclerosis 2007;194: 141146.

Petroni A, Blasevich M, Salami M, Papini N, Montedoro GF, Galli C. Inhibition of platelet aggregation and eicosanoid production by phenolic components of olive oil. Thromb Res 1995; 78:151-160.

Procopio A, Alcaro S, Nardi M, Oliverio M, Ortuso F, Sacchetta P, Pieragostino D, Sindona G. Synthesis, biological evaluation, and molecular modeling of oleuropein and its semisynthetic derivatives as cyclooxygenase inhibitors. J Agric Food Chem 2009; 57: 11161-67.

Sadeghi-Hashjin G, Folkerts G, Henricks P A, Muijsers R B, Nijkamp FP. Peroxynitrite in airway diseases. Clin Exp Allergy 1998;28:1464-1473.

Saija A, Tomaino A, Lo Cascio R, Rapisarda P, Dederen JC. In vitro antioxidant activity and in vivo photoprotective effect of a red orange extract. Int J Cosmet Sci 1998; 20: 331-42.

Salvini S, Sera F, Caruso D, Giovannelli L, Visioli F, Saieva C, Masala G, Ceroti M, Giovacchini V, Pitozzi V, Galli C, Romani A, Mulinacci N, Bortolomeazzi R, Dolara P, Palli D. Daily consumption of a high-phenol extra-virgin olive oil reduces oxidative DNA damage in postmenopausal women. Br J Nutr 2006; 95: 742-751.

Servili M, Selvaggini R, Esposto S, Taticchi A, Montedoro GF, Morozzi G. Health and sensory properties of virgin olive oil hydrophilic phenols: agronomic and technological aspects of production that affect their occurrence in the oil. J Chromatogr A. 2004; 1054: 113-27.

Soneja A, Drews M, Malinski T: Role of nitric oxide, nitroxidative and oxidative stress in wound healing. Pharmacol Rep 2005, 57:108-119.

Suárez M, Romero M-P, Macià A, Valls RM, Fernández S, Solà R, Motilva M-J. Improved method for identifying and quantifying olive oil phenolic compounds and their metabolites in human plasma by microelution solid-phase extraction plate and liquid chromatography-tandem mass spectrometry. J Chromatogr B 2009; 877: 4097-4106.

Szabo C, Dawson VL. Role of poly (ADP-ribose) synthetase in inflammation and ischaemiareperfusion. Trends Pharmacol Sci 1998;19: 287-298.

Taub DD, Conlon K, Lloyd AR, Oppenheim JJ, Kelvin DJ: Preferential migration of activated CD4+ and CD8+ T cells in response to MIP-1 alpha and MIP-1 beta. Science 1993, 260:355-358.

Trichopoulou A, Costacou T, Bamia C, Trichopoulos D: Adherence to a Mediterranean diet and survival in a Greek population. N Engl J Med 2003;348: 2599-2608.

Tripoli E, Giammanco M, Tabacchi G, Di Majo D, Giammanco S, La Guardia M. The phenolic compounds of olive oil: structure, biological activity and beneficial effects on human health. Nutr Res Rev 2005; 18: 98-112. 
Visioli F, Poli A, Galli C. Antioxidant and other biological activities of phenols from olives and olive oil. Med Res Rev 2002; 22: 65-75. 